\title{
Hermann Spieckermann Jhwh, die David-Dynastie und ihre Erben
}

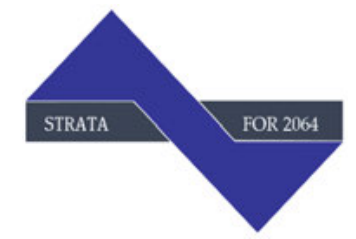

\section{Die Entdeckung des Sphärenwechsels im Psalter}

\begin{abstract}
The change of spheres in the Psalms is a discovery which results from intense theological reflection, a process that began with the loss of the Davidic dynasty. During the pre-exilic period, Zion is the site of palace and temple, a space where the spheres of God and king, heaven and earth permanently interchange. Those spheres were neither regarded as identical nor were they clearly distinguished from each other. In fact, it is impossible to bring them closer together. The loss of the Temple and of the Davidic dynasty due to the destruction of Jerusalem in 587/6 B.C.E. marks the end of the pre-exilic symbiosis. During the exile, the spheres of God and the world drift apart because the Davidic kingship as the mediating agency does not exist any longer. During the post-exilic period, the Second Temple and the personalisation of Zion gave rise to new ways how to conceptualise God's presence in the world. God himself is determined to change spheres. As divine king he is stooping down into the sphere of the destitute, who regard themselves as heirs of the lost Davidic dynasty. God raises them royally into his own sphere, granting them a permanent home in Zion-Jerusalem. The city is personified as a woman who has a unique relationship with God and, at the same time an unshakable relationship with her children, the heirs of the promises given to the Davidic dynasty.
\end{abstract}

\section{Die Fragestellung}

Das Verhältnis von Jhwhs Königtum zu den Repräsentanten der David-Dynastie, die die vorexilische Periode von Juda-Jerusalem bis zum Untergang im Jahre 587/6 v. Chr. ein halbes Jahrtausend geprägt hat, gehört in den Psalmen mit einem vorexilischen Grundbestand $\mathrm{zu}$ den bestimmenden Themen der Theolo-

\footnotetext{
Hinweis: Der vorliegende Beitrag ist im Kontext der von der DFG geförderten Forschergruppe 2064 „STRATA - Stratifikationsanalysen mythischer Stoffe und Texte in der Antike“ (Teilprojekt „Antikes Ugarit und antikes Israel: Sphärenwechsel der Macht im ugaritischen Baal-YammMot-Zyklus und in hebräischen Yhwh-König und Königs-Psalmen “) entstanden.
} 
gie des Ersten Tempels ${ }^{1}$. Unter den relevanten Texten ist die inhaltliche Nähe von Ps 2 und Ps 110 vielfach beobachtet und untersucht worden. Sie ist bedingt durch den gemeinsamen Stoff der Interaktion von Jhwh und seinem König gegen den Aufruhr von Herrschern und Feinden, von denen die Welt voll ist. Der universale Aufruhr gegen die Herrschaft des von einer Gottheit eingesetzten Königs ist im Alten Orient des 2. und 1. Jahrtausends v. Chr. belegt, schriftlich und ikonographisch besonders gut dokumentiert im Ägypten des Neuen Reiches, bekannt aber auch in den Stadtstaaten der Spätbronzezeit und später in den Königreichen der Eisenzeit auf der syrisch-palästinischen Landbrücke ${ }^{2}$. In Juda-Jerusalem kommt dabei Zion als Stätte zugleich göttlicher und königlicher Präsenz, von der die Konteraktion Jhwhs und seines Königs ihren Ausgang nimmt, eine Schlüsselfunktion zu. Die präzise Bestimmung dieser Funktion bedarf der Untersuchung. Wird Zion hier als ein klar identifizierbarer Ort ins Auge gefasst, oder ist Zion ein theologischer Topos im Sinne eines Handlungsund Herrschaftsraums, der zwar auch auf einer Landkarte zu finden ist, vor allem aber auf der mental map der Protagonisten der Königs- und Zionstheologie gesucht werden will? Die genannten Deutungsoptionen von Geographie und mythisch-theologischer Kosmographie bilden selbstverständlich keinen kontradiktorischen Gegensatz. Aber dass sie erheblich divergierende Optionen der

1 Wichtige Beobachtungen aus unterschiedlichen Perspektiven bei Mettinger 1976; Spieckermann 1989, Saur 2004; Hamilton 2005; Salo 2017; Krusche (erscheint 2019).

2 Zum rezipierten ägyptischen Hintergrund vgl. Assmann 1984, 141-149; Zenger 1986, 495-511; Koch 1993, 262-298. Im ugaritischen Baal-Yamm-Mot-Zyklus (CAT/KTU; Textedition: Dietrich/Loretz/Sanmartín 1995, 1-30; Übersetzung: Niehr 2015, 177-236) ist das mythische Motiv des Kampfes um die Königsherrschaft zunächst zwischen Baal und Yamm, sodann zwischen Baal und Mot Träger der Handlung; auch Anat, Baals Geliebte und Protagonistin, ist in den Kampf um die Königsherrschaft involviert (CAT/KTU 1.3 II). Ihre Kampfbereitschaft gilt offenkundig als Ausweis ihrer Macht. Anat wird Baal am Ende des Zyklus aus dem Machtbereich des Totengottes Mot holen - allerdings mit Hilfe der Sonnengöttin Šapšu, welcher auch bei dem Kampf Baals gegen Mot um die Königsherrschaft die entscheidende Rolle zukommt (CAT/KTU 1.6 I,6-31; III,10-VI,53). Dieser Stoff ist nach Palästina wahrscheinlich vor allem über die großen Hafenstädte an der Ostküste des Mittelmeeres gelangt, über die auch der Austausch zwischen ägyptischen und altsyrischen, später phönizischen Traditionen seit dem 2. Jahrtausend v. Chr. erfolgt ist (vgl. Helck 1979, 106-255; Stadelmann 1967). Zudem haben die Städte in der JesreelEbene eine besondere Bedeutung gehabt. Auch diese Region ist am Kulturtransfer über Jahrhunderte hin lebhaft beteiligt gewesen und hat alttestamentliche Theologiebildung nachhaltig beeinflusst. Dies gilt nicht zuletzt für die Erhellung theologischer Vorstellungen im Bereich der (Gott-) König-Theologie (grundlegend: Schmidt ${ }^{2} 1966$ ).

In diesem komplexen Kulturtransfer haben gewiss auch mesopotamische Einflüsse eine Rolle gespielt. Sie werden nicht weiter verfolgt, weil sie hier gegenüber den oben genannten von geringerer Relevanz gewesen zu sein scheinen. 
Deutung und Bedeutung benennen, leidet keinen Zweifel. Die sich stellenden Probleme können auf folgende Fragen zugespitzt werden: Wie verhält sich der göttliche Himmelsthroner zu dem auf dem Zion inthronisierten König? In welche Relation werden Himmel und Zion, Herrschaft begrenzten Umfangs (Zion/Jerusalem) und Weltherrschaft gebracht? Ist der auf Zion eingesetzte König Sohn eines königlichen Gottes, den dieser aus seiner himmlischen Sphäre entlässt, um ihn im Sinne einer Katabasis auf dem Zion als einem weltlich lokalisierbaren Ort zu inthronisieren? Oder ist die Inthronisation auf dem Zion eher im Sinne einer Anabasis zu verstehen, durch die der Himmelsherrscher seinen irdischen Mandatar auf Zion als Stätte exzeptioneller Gottesnähe erhöht und Zion zugleich die mythisch-kosmische Aura des Zentrums der Welt verleiht?

Das Kernproblem liegt in der Frage nach dem Zion und seiner Bedeutung für die spezifische Relation von Jhwh und seinem König. Klärung ist von der möglichst präzisen Erfassung des in Ps 2 und 110 angedeuteten Geschehens sowie der Rolle der jeweiligen Handlungsträger zu erwarten. Dass die Konfrontation zwischen Jhwh und seinem König einerseits und den Aufständischen andererseits stattfindet, ist evident. Welche Aufgabe jedoch Jhwh selbst und welche sein König an welchem Ort übernimmt, muss untersucht werden. Die Klärung wird nicht zuletzt davon abhängen, ob den beiden Schlüsseltexten eine rekonstruierbare identische Handlungsabfolge zugrunde liegt oder ob sie sich eine solche wechselseitige Verständnishilfe nicht gewähren. Wie immer das rekonstruierte Geschehen zu charakterisieren ist, bleibt zu klären, ob es sich eher um ein singuläres oder ein auf Wiederholung angelegtes Geschehen, nämlich um ein bestimmtes Ritual oder die Erinnerung daran handelt.

So wenig es gelingen will, Ps 2 und 110 im Psalter und anderen alttestamentlich-jüdischen Schriften einen weiteren Text ähnlichen Inhalts an die Seite zu stellen, so sehr legt sich die Vermutung nahe, dass besonders ein in beiden Texten präsentes Motiv in einigen jüngeren Psalmen aufgegriffen und theologisch neu bestimmt worden ist. Es handelt sich um die Interaktion zwischen Jhwh und seinem König. Dass gerade dieses Motiv zu einer Aktualisierung eingeladen hat, kann angesichts des Verlustes der davidischen Dynastie durch die von den Neubabyloniern im Jahre 587/6 geschaffenen Verhältnisse nicht verwundern. Für den verlorenen König stehen Erben bereit, die in das dem König gewährte Verhältnis eintreten wollen. Hier gewinnt der Sphärenwechsel im Unterschied zu den Spendertexten Ps 2 und 110 deutlich Gestalt. Unter diesem Aspekt sollen abschließend Jes 63,7-64,11; Ps 80 und Ps 113 in den Blick genommen werden, Texte, die ihrerseits eine wirkmächtige Rezeption erfahren haben. 


\section{Der Himmelsthroner und sein Sohn auf dem Zion in Psalm 2}

Ps 1 eröffnet zusammen mit Ps 2 den Psalter ${ }^{3}$. Dass beide Psalmen gleichwohl ihre je eigene Herkunft haben, ist unübersehbar. Ps 1 sucht evident die Anbindung des Psalters an Mose als Geber der Tora und an die Propheten als Sachwalter der Tora. Ps 1 will deutlich machen, dass im Psalter Beter willkommen sind, die bereits die Tora zum Zentrum ihres Lebens gemacht haben (Ps 1,1 f). Demgegenüber präsentiert Ps 2 den universalen Aufruhr der Könige der Erde gegen Jhwhs universale Herrschaft, welchem dieser durch eine Konteraktion souverän und wirkungsvoll begegnet: durch die Einsetzung seines Königs als Sohn auf dem Zion. Diese Handlung macht jedes weitere Wort über den Aufruhr überflüssig, nicht aber die Mahnung an die Herrscher der Erde in Ps 2,10-12, jeden weiteren Versuch in Zukunft zu unterlassen. Glückselig sind allein die zu preisen, die als Tora-Liebhaber Gottes Nähe auch im Gebrauch der Psalmen suchen (Ps 1). Wer aber wie die Könige der Erde zum Kreis der Tora-Fernen gehört, lasse sich warnen, den universalen Herrschaftsanspruch des Himmelsthroners und seines Messias-Sohnes $\mathrm{zu}$ missachten. Unter den irdischen Herrschern sind nur die glückselig zu preisen, die bei ihm - sei es bei Jhwh, sei es beim königlichen Messias-Sohn - Zuflucht suchen (Ps 2,12d). Durch die Glückseligpreisungen am Anfang von Ps 1 und am Ende von Ps 2 werden die beiden Texte, die selber der Form nach keine Gebete sind, als Paar verbunden und zum Introitus des Ersten Davidpsalters (Ps 3-41) gemacht, eine Position, die ihnen bis zum Abschluss des ganzen Psalters erhalten geblieben ist. Bis in die Endgestalt von Ps 1 und 2 ist jedoch mit Händen zu greifen, dass die Ehe dieser beiden Texte nicht im Himmel, sondern in der Geschichte des wachsenden Psalters angesichts der Notwendigkeit geschlossen worden ist, im Introitus deutlich zu sagen, dass die toranahen Gerechten wie die gottfernen Frevler und Herrscher dieser Erde Gott und seinem Willen begegnen können, wenn sie von der Sammlung der Psalmen Gebrauch machen. Ist die Verschiedenheit der Adressaten und der jeweils an sie gerichteten Botschaft in Ps 1 und 2 auch unübersehbar, wird durch das einleitende Textpaar nachdrücklich betont, dass die dem Gott Jhwh Nahen und Fernen von den Psalmen mit Gewinn Gebrauch machen können, weil die Gebete das Gottesverhältnis des Einzelnen und der Völkerwelt begleiten und bedenken. Individual- und Universalperspektive des Betens wer-

3 Zum Textpaar Ps 1 und 2 und seiner reichen Rezeptionsgeschichte vgl. Cole 2013; Gillingham 2013; vgl. auch Hartenstein/Janowski 2012, 1-54. 
den durch Ps 1 und 2 dem Psalter als Doppelbestimmung programmatisch vorangestellt. Die sich darin widerspiegelnde theologische Komplexität des Psalters lässt sich durch keine einengende Charakterisierung des Psalters, wie sie immer wieder unternommen wird, angemessen einfangen. Will man der Komplexität gerecht werden, darf man sich nicht an punktuellen Beobachtungen wie vermuteten Trägerkreisen und Redaktionsprozessen orientieren, die für die Eigenart des Psalters allesamt ephemer sind, vielmehr muss man die theologische Pointierung wagen. In dieser Hinsicht ist die im Judentum unweit der Zeitenwende ersonnene Titulierung des Psalters als těhillîm „Preisungen“ (Jhwhs) schwer zu überbieten ${ }^{4}$.

Während es bei Ps 1 wahrscheinlich ist, dass der Text gezielt als Introitus des Psalters komponiert worden ist, ist dies bei Ps 2 auszuschließen. Zwar verbindet Ps 2 mit Ps 1 der negative Befund, dass beiden elementare Sprechakte des Betens wie Anrufung, Klage und Bitte, Dank und Lob(versprechen) fehlen. Dem ist kein positiver Befund an die Seite zu stellen, der die Nähe beider Texte augenfällig machte. Vielmehr vermittelt Ps 2 nachhaltig den Eindruck, dass seine formale und inhaltliche Geschlossenheit anderer Art als diejenige von Ps 1 ist. Handelt es sich bei Ps 1 um einen klar aufgebauten Introitus mit unverkennbar appellativem Charakter, die Gemeinschaft der Gerechten in der Liebe zur Tora und im Gebrauch der Gebete zu suchen, präsentiert Ps 2 eine groß dimensionierte, agonale Handlung in vier Strophen mit je drei wohlproportionierten Bikola. Die leicht erkennbaren Wachstumsspuren sind in der folgenden Übersetzung in eckige Klammern gesetzt worden ${ }^{5}$.

(1a) Warum planen die Völker Aufruhr

(1b) und sinnen die Nationen Nichtiges?

(2a) Es erheben sich die Könige der Erde,

(2b) und Fürsten tun sich zusammen

(2c) [gegen Jhwh und seinen Gesalbten]: ${ }^{6}$

(3a) „Lasst uns ihre Bande zerreißen

(3b) und ihre Stricke von uns werfen!“

(4a) Der im Himmel thront, lacht,

(4b) es spottet ihrer der Herr.

4 Die ältesten Belege sind in Qumran bezeugt: 4Q196 Frag. 17 II,7; 11Q5 XXVII,4-5 (García Martínez / Tigchelaar 1997, 386-387.1178-1179).

5 Zu Ps 2 vgl. Zenger 1986, 495-511; Hossfeld/Zenger 1993, 49-54; Saur 2004, 25-46; Feldmeier/ Spieckermann 2018, 90-94.

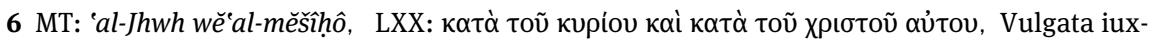
ta Hebraicum: adversum Dominum et adversum christum eius. 
(5a) Dann fährt er sie an in seinem Zorn

(5b) und verstört sie in seinem Grimm:

(6a) „Ich selber setze meinen König ein

(6b) auf Zion, meinem heiligen Berg.“

(7a) [Ich will künden von Jhwhs Satzung.]

(7b) Er spricht zu mir: „Mein Sohn bist du.

(7c) Ich selber habe dich heute geboren.

(8a)Bitte mich, so will ich Völker zu deinem Erbe geben

(8b) und zu deinem Besitz die Enden der Erde.

(9a) Du wirst sie zerschlagen mit eisernem Zepter ${ }^{7}$,

(9b) wie Töpfergeschirr sie zerschmettern.“

(10a) „Und nun, ihr Könige, nehmt Vernunft an,

(10b) lasst euch warnen, ihr Herrscher der Erde.

(11a) Dient Jhwh in Furcht,

(11b) frohlockt mit Zittern,

(12a) [küsst den Sohn,]

(12b)damit er nicht zürne und ihr umkommt [auf dem Weg],

(12c) denn leicht entbrennt sein Zorn.“

(12d)[Glückselig alle, die bei ihm Zuflucht suchen.]

Die in der Übersetzung kenntlich gemachte vierstrophige Gliederung entspricht den vier Szenen, die der Psalm in den Blick nimmt ${ }^{8}$. Betrachtet man die ermittelte Grundfassung, steht eine sich leicht erschließende Szenenfolge vor Augen.

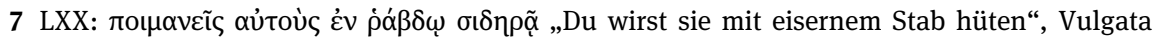
iuxta LXX: reges eos in virga ferrea, Vulgata iuxta Hebraicum: pasces eos in virga ferrea.

8 In der ersten Strophe ist V. 2c „gegen Jhwh und seinen Gesalbten“ hinzugefügt worden, denn die Identifizierung derjenigen, gegen die sich die Erhebung der Völker und Herrscher der Welt richtet, kommt nun im Text zu früh. Gegen die Einschätzung als Fortschreibung kann nicht als Gegenargument angeführt werden, dass V. 2c notwendig sei, um zu wissen, von wessen Banden und Stricken sich die Gefesselten befreien wollen. Es gehört vielmehr zur Dramaturgie dieses Textes, dass in der ersten Strophe die Adressaten des Aufruhrs ungenannt bleiben und sie erst in der Konteraktion ihren Auftritt haben. Natürlich sind keine anderen als Jhwh und sein König aus der zweiten Strophe gemeint. Der Grundtext bietet gerade durch die Leerstellen eine überlegte literarische Inszenierung, die Spannung erzeugt.

In der dritten Strophe ist V. 7a eine später eingefügte Erläuterung der zwischen Jhwh und dem König bereits in Gang befindlichen Handlung. Die Ergänzung will festhalten, dass Jhwhs Einsetzung des Königs nicht eine einmalige Handlung, sondern die dauerhafte Bestimmung seines Verhältnisses zu jedem König auf seinem heiligen Berg Zion ist.

Schließlich ist die vierte Strophe V. 10-12 um einige Hinzufügungen bereichert worden. Das im Alten Testament singuläre Küssen des Sohnes in V. 12a ist möglicherweise als Ergebenheitsbekundung gemeint und gewiss auf den von Jhwh eingesetzten König bezogen. Doch der Sohn, der in V. 7b mit dem hebräischen Wort bēn bezeichnet wird, firmiert hier unter dem 
In der ersten Strophe (V. 1-3) fragt eine nicht genannte Person nach dem Grund für den Aufruhr, den Völker und Könige angezettelt haben. In Vers 3 kommen die Aufständischen selbst mit ihrer Absicht zu Wort, sich der Fesseln ihrer nicht genannten Herrscher zu entledigen. In der zweiten Strophe (V. 4-6) reagiert der bisher nicht genannte Himmelsthroner. Sein spöttisches Lachen und sein entflammter Zorn gipfeln in der Ankündigung der Konteraktion, der Einsetzung seines Königs auf Zion. Dies reicht bereits aus, die Rebellen zu paralysieren. In der dritten Strophe (V.7-9) teilt der eingesetzte König die an ihn ergangene Gottesrede mit. Seine Inthronisierung auf Zion gipfelt in der göttlichen Gewährung des Vater-Sohn-Verhältnisses ${ }^{9}$, eine Bestätigung der außerordentlichen Gottesnähe, die schon vorher bei der Einsetzung des Königs auf dem heiligen Berg durch den Himmelsthroner kundgetan worden ist und nun durch die Metapher der in diesem Akt stattfindenden Geburt durch Gott nachhaltig unterstrichen wird. Seinem Sohn liest Gott jeden Wunsch von den Lippen ab. Weil Gott dies immer getan hat, stehen die Wünsche des Königs längst im Ritual, so dass Gott die Wunschliste des Königs gar nicht abwarten muss, sondern gleich selbst die Wünsche nennen und ihre Erfüllung zusagen kann. Diese Gottesrede ist in Vers 7b-9 freilich so inszeniert, dass es der König ist, der diese an ihn ergangene Gottesrede in dem hier gesetzten Rahmen mitteilt. Die Inszenierung gibt sich spätestens in dieser Strophe als königliches Inthronisationsritual zu erkennen, dessen Elemente nicht in Jerusalem erfunden, sondern aus längst

aramäischen Äquivalent bar. Die gern akzeptierte Emendation ,und mit Zittern küsst seine Füße“ anstelle von „frohlockt mit Zittern, küsst den Sohn“, die von Bertholet 1908, 58-59 stammt, ist gewiss falsch, weil die Vorstellung, Jhwh die Füße zu küssen, alttestamentlichjüdisch undenkbar ist. Bezeichnenderweise hat die Septuaginta in ihrer hebräischen Vorlage

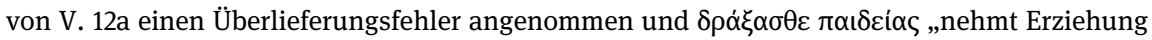
an" übersetzt, wahrscheinlich in der Annahme, dass die im Masoretischen Text gut bezeugte Kombination von lqh mit mûsār „Erziehung annehmen“ verschrieben worden ist (vgl. Jer 2,30; 5,3; 7,28; 17,23; 32,33; 35,13; Zeph 3,2.7; Prov 1,3; 8,10; 24,32).

Sodann sind in der vierten Strophe noch als Verbindungselement zu Ps 1 der Weg (vgl. Ps 2,12b mit Ps 1,6) und die Glückseligpreisung (vgl. Ps 2,12d mit Ps 1,1) hinzugefügt worden.

9 Dieses Verhältnis hat seine nächste Parallele in 2Sam 7,14a; vgl. Feldmeier/Spieckermann ${ }^{2} 2017,56-66$.

Die Septuaginta hat die Sprecherrollen in Ps 2,4-9 zugunsten des Königs modifiziert. Wahrscheinlich wird vom Übersetzer angenommen, dass die ganze zweite Strophe V. 4-6 vom König gesprochen wird, denn in V. 6 wird Jhwh die Rolle des Sprechers, die er im Masoretischen Text innehat, entzogen. Die griechische Version lässt in V. 6 den König sprechen und verbindet damit sogleich V. 7a: „Ich selber bin eingesetzt worden als König durch ihn auf Zion, seinem heiligen Berg, indem ich die Satzung des Herrn verkündige. "Daran schließt in V. 7b die Gottesrede an, was in ihrer Einleitung durch Nennung des Kyrios eindeutig gemacht wird: „Der Herr sprach zu mir. " 
bestehenden Königsritualen übernommen worden sind, aller Wahrscheinlichkeit nach vor allem aus dem Ägypten des Neuen Reiches, freilich in einer Synthese mit altsyrisch-phönizischem Einfluss ${ }^{10}$. Ist dem König bereits hier gefestigte Herrschaft und erfolgreiche Abwehr jeder Bedrohung zugesagt worden, verwundert es nicht, in der vierten Strophe (V. 10-12) seine abschließende Mahnung an die Könige und Herrscher der Erde zu finden, dem schnell zu erzürnenden Gott Jhwh mit Furcht und Zittern und zugleich mit Frohlocken zu dienen.

$\mathrm{Zu}$ Recht kann man darüber verwundert sein, dass in dieser letzten Strophe die Ergebenheit Jhwh und nicht dem auf dem Zion eingesetzten König gilt, welcher in Vers 12a unbeholfen nachgetragen worden ist. Es ist deshalb erwogen worden, die letzte Strophe insgesamt als nachexilischen Anhang an einen vorexilischen Königspsalm zu betrachten ${ }^{11}$. Doch die vorangehenden drei Strophen wären ohne die vierte kein vollständiger Psalm. Deshalb ist es wahrscheinlich, dass Ps 2 immer eine vierstrophige Grundfassung gehabt hat. Die Königs- und Inthronisationstheologie mit der Inauguration des Vater-SohnVerhältnisses durch Geburt, das Jhwh dem jeweiligen Repräsentanten der Daviddynastie gewährt, samt der Erhaltung der Herrschaft gegen die Bedrohung durch andere Mächte ist dem Inhalt nach vorexilisch, ohne dass die vorexilische Fassung dem Wortlaut nach zu rekonstruieren möglich wäre. Die Konzentration der vierten Strophe allein auf die Jhwh-Furcht, die den Herrschern der Welt angeraten wird, spiegelt in der Tat eher die Verhältnisse der Zeit nach dem Verlust der Daviddynastie wider. Die nicht mehr erhaltene, vorexilische Fassung der vierten Strophe hat vermutlich von dem gesprochen, der von Jhwh als König und Sohn auf dem Zion eingesetzt worden ist. Durch die allein bezeugte Änderung der vierten Strophe und weitere Reformulierungen ist der Psalm der Theologie des Zweiten Tempels angepasst und dadurch wie auch viele andere Psalmen weiter verwendbar geblieben. Die Warnung vor dem nicht mehr existenten Repräsentanten der davidischen Dynastie wäre ein Anachronismus gewesen,

10 Vgl. Brunner ${ }^{2} 1986$; Koch 2002.

Der Einfluss aus dem altsyrisch-phönizischen Raum ist in der Bedeutung des heiligen Berges und in dem Epitheton Himmelsthroner für Jhwh erkennbar. Nach dem Untergang Ugarits um 1185 v. Chr. hat Baal nördlich und südlich von Ugarit und im aufstrebenden Phönizien zunehmend $\mathrm{El}$ aus der Rolle des summus deus verdrängt. Ist Baal in der Amarnakorrespondenz schon als „Baal im Himmel“ bezeugt, begegnet er als „Baal des Himmels“ bereits in einer phönizischen Inschrift aus Byblos um 950 v. Chr., ein Vorläufer seines phönizischen Namens Baalšamem (vgl. Niehr 2003; ders. 2015, 188). Wahrscheinlich hat Jhwh die himmlische Existenz auch schon von Baal in vorexilischer und nicht erst in persischer Zeit von Ahuramazda gelernt.

11 Vgl. Hossfeld/Zenger 1993, 50-54. 
der weder Freund noch Feind beeindruckt hätte. Auch die Hinzufügung von Vers 2c „gegen Jhwh und seinen Gesalbten“ dient der Aktualisierung des Psalms in nachexilischer Zeit, denn die kollektive Applikation des Messias auf das in der Diasporaexistenz sich neu formierende Gottesvolk begegnet in den folgenden Psalmen immer wieder (Ps 18,51 = 2Sam 22,51; Ps 20,7; 28,8; 84,10; 89,52; 105,15; 132,17; vgl. Hab 3,13) ${ }^{12}$. Ps 2,2c will in Kenntnis dieser Texte vorab Nähe und Unzertrennlichkeit von Jhwh und seinem Gesalbten betonen ${ }^{13}$. Nimmt man alle Bestimmungen des Verhältnisses Jhwhs zu seinem auf dem Zion eingesetzten Mandatar in Ps 2 zusammen, verwundert das theologische Gewicht nicht, das diesem Text im Judentum der Zeitenwende (4 Q 174 III,18-IV,3; PsSal 17,23-24) und bei der Deutung der Person Jesu (Mk 1,11; Mt 3,17; 4,3; Lk 3,22; Joh 1,34.49; Apg 13,33; Hebr 1,5; 5,5) beigemessen worden ist.

Nachdem die Literargeschichte von Ps 2 soweit wie möglich erhellt worden ist, kann man mit hoher Wahrscheinlichkeit davon ausgehen, dass dieser Text am Ersten wie am Zweiten Jerusalemer Tempel eine hohe Wertschätzung genossen hat. Die unterschiedlichen Sprecherrollen weisen auf ein Ritual der Königstheologie der davidischen Dynastie der vorexilischen Zeit, welches für den Zweiten Tempel der nachexilischen Zeit vor allem durch die vierte Strophe theozentrisch profiliert und durch die Identifikation des Königs mit dem korporativ verstandenen Messias in Gestalt des Gottesvolkes in Jerusalem und überall in der Welt theologisch aktualisiert worden ist. Für die vollständig vorliegende, nachexilische Version von Ps 2 gilt zwar immer noch, dass die rebellierenden Herrscher der Erde (V. 3) und Jhwh (V. 6) zu Wort kommen, aber der Vortrag des ganzen Psalms ist am besten allein durch einen hochrangigen Priester am Zweiten Tempel vorstellbar. Schon in den ersten beiden Strophen nimmt ja trotz des Mediums der wörtlichen Rede ein Außenstehender das Geschehen in eindeutig

12 Im eschatologischen Midrasch 4 Q 174 III,18-19 wird Ps 2,1-2 als Rebellion der Völker [ $\left.{ }^{l}\right]$ bhyry Yśr'l b’ḥryt hymym ,gegen die Erwählten Israels am Ende der Tage“ gedeutet; vgl. García Martínez / Tigchelaar 1997, 354-355; Steudel 1994, 5-56 (Text 25.32).

13 Diese Nähe wird in der Septuaginta durch einen weiteren Aspekt unterstützt. Die in den Psalmen und verwandten Texten nicht seltene Charakterisierung Gottes als gut (țôb) wird in der Septuaginta durchgängig mit $\chi \rho \eta \sigma \tau o ́ \varsigma$, gut, gütig“ wiedergegeben. Angesichts des im

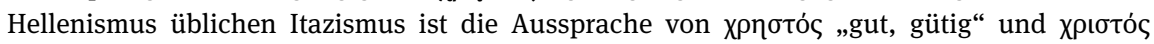

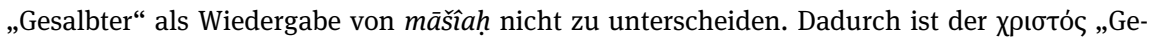

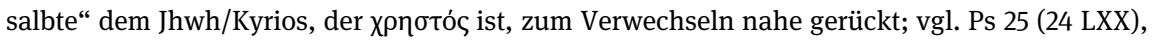

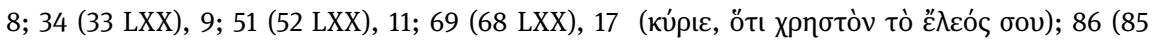
LXX), 5; 100 (99 LXX), 5; 106 (105 LXX), 1; 107 (106 LXX), 1; 109 (108 LXX), 21; 119 (118 LXX), 68; 136 (135 LXX), 1; 145 (144 LXX), 9; SapSal 15,1: PsSal 2,36; 5,2.12; 8,32; 10,2.7; Nah 1,7; Jes 40,11; Dan 3,89; 2 Makk 1,24. 
wertender Perspektive wahr, und in den beiden letzten Strophen ist ein priesterlicher Sprecher geradezu geboten. Denn die Einleitung der dritten Strophe in Vers 7a „Ich will künden von Jhwhs Satzung“ setzt für das Folgende einen einzigen Sprecher voraus. In Vers $7 \mathrm{~b}-9$ sind dann die Redeanteile sowohl des bittenden Königs als auch des gewährenden Gottes Jhwh in der Form der Gottesrede vereinigt. Hier gibt der Psalm also nicht den Ritualtext wieder, sondern fasst diesen in seinem wesentlichen Inhalt zusammen. Kein anderer als ein Priester kann diese Passage sprechen. Und die vierte Strophe in Vers 10-12 nennt die Herrscher der Erde und Jhwh gleichermaßen, so dass auch hier nur der Vortrag desselben Priesters in Frage kommt.

Es dürfte für die vorliegende nachexilische Fassung von besonderem theologischem Gewicht sein, dass der Himmelsthroner und sein heiliger Berg Zion in der zweiten Strophe (V. 4-6) so eng aneinander gerückt werden, dass eine räumliche Unterscheidung von Himmel und heiligem Berg durch nichts befördert wird. Kein Verb der Bewegung und keine Lexeme, die räumliche Nähe oder Distanz vermitteln, werden gebraucht. Zion als heiliger Berg bietet dem messianischen Gottesvolk Raum, das sich in den Mantel des Repräsentanten der einstigen Daviddynastie gekleidet hat. Der damit identische Zion - im Hebräischen feminin im Unterschied zum maskulinen Genus von har „Berg“ - gewährt dem Gottesvolk Schutz inmitten einer feindseligen Welt. Was die Herrscher dieser Erde samt ihren Völkern noch lernen müssen, ist dem Gottesvolk in der weltweiten Diaspora längst Gewissheit geworden: Auf dem heiligen Berg des Himmelsthroners sind alle die glückselig zu preisen, die Zuflucht bei Jhwh gesucht und gefunden haben - wo immer sie in der Welt leben. Der Zion ist in Jerusalem lokalisiert und zugleich theologischer Topos, der überall in der Welt die bergende Kraft Jhwhs gewährt. Die kombinierten Vorstellungen Zion und heiliger Berg haben eine Raum und Zeit sprengende Potenz. Diese ist - wie gleich zu zeigen sein wird - auch schon in vorexilischer Zeit nicht unbekannt. Doch in der nachexilischen Zeit eröffnet sie dem in der Welt zerstreuten Judentum noch einmal eine neue Dimension des Selbstverständnisses. Der heilige Berg Zion ist das Zentrum der ganzen Welt ${ }^{14}$, in der die Juden leben - in der Regel weit davon entfernt und ohne Aussicht, ihn je sehen zu können - und zugleich Zentrum der erfahrbaren Nähe Jhwhs, weil Zion überall dort gegenwärtig wird, wo Gottesfürchtige Ps 2 bei ihren Zusammenkünften beten.

Demgegenüber wird die vorexilische Fassung von Ps 2 Teil eines Rituals gewesen sein, das (die jährliche Erinnerung an) die Inthronisation des jeweili-

14 Dieses Motiv kann mit Zion auch als Stadt verbunden werden. Dies ist prominent der Fall in Jes 60-62; vgl. Spans 2015. 
gen Königs auf dem Davidsthron zum Inhalt hat. Die vorexilische Fassung ist nicht mehr zu rekonstruieren, aber die Eigentümlichkeiten der vorliegenden Endfassung geben zu erkennen, wo die ältere Fassung in Wortlaut und Arrangement wahrscheinlich Unterschiede aufgewiesen hat. Dies betrifft vor allem die Rolle des Königs im Ritual. Es ist gut möglich, dass die beiden ersten Strophen (V.1-3 und V.4-6) von zwei Priestern gesprochen worden sind. Die Stimme, die nach dem Grund des weltweiten Aufruhrs fragt, bekommt von der Stimme, die - in Gegenwart des Königs - die Einsetzung des Königs auf Zion im Namen des Himmelsthroners mitteilt, eine Antwort. In der dritten Strophe (V. 79) legt es sich nahe, dass es an dieser Stelle in der vorexilischen Fassung einen kurzen, ritualisierten Dialog zwischen dem Priester, der in Gottes Namen spricht, und dem König gegeben hat. Nach der als Gottesrede vorgetragenen Gewährung der Sohnschaft hat wahrscheinlich der König die im Formular festgelegten Wünsche gesprochen, die der Priester in Gottes Namen formelhaft gewährt. Die abschließende vierte Strophe (V.10-12) wird in der nicht erhaltenen, alten Fassung wieder einer der beiden beteiligten Priester, vielleicht der für die erste Strophe verantwortliche, gesprochen haben. Seine abschließende Adresse an die rebellischen Könige wird nicht eine Aufforderung zur JhwhFurcht, sondern eine Warnung gewesen sein, die Macht des als Sohn Gottes auf dem Zion eingesetzten Königs nicht auf die Probe zu stellen. Zur Zeit der bestehenden Daviddynastie wäre die vorhergehende (vergegenwärtigende Erinnerung an die) Inthronisation ohne jeden Effekt auf die eingangs geschilderte Revolte gewesen, hätte nicht eben jener König die Rolle wahrgenommen, die Wohlordnung der Welt gegen die jederzeit aufbegehrenden Herrscher der Erde zu gewährleisten. Dass er es - wenn man den erhaltenen Wortlaut der vierten Strophe partiell auch für die ältere Version voraussetzen darf - in leicht entbrennendem Zorn tun wird (V.12bc) wie vorher der Himmelsthroner selbst (V. 5), spricht noch einmal für die enge Verbindung zwischen Jhwh und seinem König. Der auf dem Zion eingesetzte Sohn Gottes teilt den heiligen Berg mit Gott selbst; und dieser muss als Himmelsthroner nicht den Ort wechseln, um auf dem Zionsberg gegenwärtig zu sein ${ }^{15}$. Die Vorstellung eines Sphärenwechsels -

15 Vgl. Janowski 2001, 229-260. Nicht von ungefähr ist es der Berg Zion, der mit der Vorstellung der Heiligkeit in Verbindung gebracht wird. Heiligkeit ist umfassend in der aus Ugarit bekannten altsyrischen Tradition bezeugt: für Gottheiten, Tempel, Berge (Zaphon) und Kultpersonal. Überall findet die Wurzel qdš in unterschiedlich vokalisierten Lexemen Verwendung (vgl. del Olmo Lete / Sanmartín 22004, 695-697 sub voce qdš I-IV; 788 sub voce șpn). Vom Zion her ist in nachexilischer Zeit Jerusalem in die Sphäre der Heiligkeit einbezogen worden. Jerusalem wird zur heiligen Stadt und zunehmend mit Zion identisch (Jes 48,2; 52,1; Dan 9,24; vgl. 
sei es einer Katabasis des Himmelsthroners auf den Zion, sei es einer Anabasis des Königs als Sohn Gottes an diesen Ort - hat an der belegten nachexilischen wie an der rekonstruierbaren vorexilischen Fassung von Ps 2 keinen Anhalt. Auch implizit ist ein Sphärenwechsel weder vorausgesetzt noch intendiert. Vielmehr soll man verstehen, dass Jhwh als Himmelsthroner gerade dadurch König auf Zion ist, dass er den jeweiligen König der Daviddynastie als seinen Sohn auf Zion im Akt der (Erinnerung an die) Inthronisation gebiert. Enger lässt sich das Verhältnis von König Jhwh und seinem davidischen König nicht zu Wort bringen, ohne dass das Missverständnis einer für alttestamentliche Verhältnisse problematischen Identifizierung der beiden Könige drohte.

Für die räumliche und zeitliche Zusammenschau der Orte der Gottespräsenz hat unter den bekannten Texten am ehesten Ps 48 die entscheidende Vorarbeit geleistet ${ }^{16}$. Hier wird in Vers 2-4 Jhwhs heiliger Zionsberg mit dem altsyrischen, in der Nähe von Ugarit gelegenen Gottesberg Zaphon und der „Stadt des großen (Gott-)Königs“ identifiziert, der „Freude der ganzen Erde“ und gleichwohl gefährdet durch den Aufruhr der Könige der Erde (V.5-8). Ist sogar der Zaphon zum Zion gekommen, werden dort gewiss auch die Paläste des göttlichen Großkönigs Raum finden, um den Herrschern der Welt $\mathrm{zu}$ verdeutlichen, von welchem Zentrum die wahre Macht ausgeht. Der göttliche Großkönig bedarf hier des davidischen Königs nicht, weil Gott auf Zion-Zaphon sowohl Tempel, Paläste und Stadt füllt. Doch dies legt nicht den Schluss nahe, die Grundfassung von Ps 48 gehöre nicht mehr in die vorexilische Zeit. Näher liegt die Vermutung, dass sich die Jhwh-König-Theologie und die Königstheologie der Daviddynastie in vorexilischer Zeit so harmonisch ergänzen, dass denkbare theologische Spannungen ein Anachronismus sind, für die spätere deuteronomistische Theologie verantwortlich ist. Dass in nachexilischer Zeit abgesehen von einer reichen Davidrezeption nur die Jhwh-König-Theologie überlebt hat, liegt nahe, da gerade sie unter Gebrauch der tradierten Vorstellungen ein großes Adaptionspotential unter Beweis gestellt hat.

In diesen Kontext gehört auch das Meerlied in Ex 15,1-18 ${ }^{17}$. Hier bahnt Jhwh durch seinen Kampf gegen die mythischen Mächte des Chaoswassers und der Unterwelt dem in Ägypten unterdrückten Gottesvolk einen Weg durchs Schilfmeer und durch die feindliche Völkerwelt, so dass die Geretteten schließlich

64,9-10; Sach 8,3; Ps 48,2-4; Dan 9,16.26; Neh 11,1.18). Nie werden Sinai und Horeb heilig genannt; nicht einmal Ps 68,18 kann als Gegenbeispiel dienen.

16 Vgl. Spieckermann 1989, 186-196; unter gleichzeitiger Berücksichtigung von Ps 46 und 87 vgl. Spieckermann 1992, 1-31; Körting 2006, 165-186.

17 Vgl. Spieckermann 1989, 96-115; Berner 2010, 389-400. 
Jhwhs Heiligtum auf dem Berg erreichen, wo dieser ewig als König thront und nun seinem geretteten Volk ewige Bleibe gewährt. Der Berg ist dem Zaphon, Baals Palast-Berg, verwandt, aber hier ist natürlich Zion als Weltenberg von Jhwhs Gott-Königtum gemeint, welcher freilich nicht Zion genannt werden darf, weil dies in der Exoduserzählung ein Anachronismus wäre. Dies verhält sich anders in der Verheißung des weisen Herrschers aus Isais Stumpf in Jes 11,1-9, dessen neue Herrschaft den Schwachen und Elenden des Landes zugute kommt (V.4) und einen Frieden zwischen den Geschöpfen visionär erhofft, der die gute Schöpfung von Gen 1 überbieten und die postlapsarische Welt prägen wird, „denn sie werden nichts Böses tun und nicht verderbend handeln auf meinem ganzen heiligen Berg, denn die Erde wird voll der Erkenntnis Jhwhs sein" (Jes 11,9; vgl. 65,25). Diese neue Dimension der Erkenntnis Jhwhs auf seinem heiligen Berg lässt die von Gott verbotene, aber vom Vergottungswahn des Menschen begehrte Erkenntnis der Bestimmung und Unterscheidung von Gut und Böse aus dem Garten Eden in Gen 2-3 entschlossen hinter sich ${ }^{18}$. Jhwhs heiliger Berg ist nicht nur kosmischer Topos im Sinne einer Welt bildenden Theologie, sondern er ist immer entschiedener Topos von Hoffnungen geworden, die das Gottesvolk und die Welt umfassen und die die Geburt des Gottesvolkes genauso radikal neu denken wie sie die Protologie der Welt entschieden in eine unerhörte und ungeahnte Eschatologie transformieren.

\section{Sessio ad dexteram auf dem Zion in Psalm 110}

Ps 110 ist im werdenden Psalter wahrscheinlich als Pendant zu Ps 2 aufgenommen und wie andere Vorgänger und Nachfolger mit der Absicht platziert worden, der Psalmensammlung einen markanten Abschluss zu geben, der, verglichen mit Ps 2, die Nähe zwischen Gott und König noch einmal zu überbieten sucht. Durch die Fortschreibung von Ps 110,4 wird zudem die Verbindung mit dem Priestertum Melchisedeks hergestellt, welcher nach der schon formierten Erzählsequenz der autoritativen Schriften die erste priesterliche Gestalt ist, die in Gottes Geschichte mit seiner Schöpfung auftritt, verbunden mit keinem Geringeren als Abraham (Gen 14,18-20) ${ }^{19}$.

Ps 110 hat eine deutlich kompliziertere Entstehungsgeschichte als Ps 2 gehabt. Zur größeren Unsicherheit der Eruierung eines sehr wahrscheinlich noch

$18 \mathrm{Zu}$ Jes 11,1-9 vgl. Feldmeier/Spieckermann 2018, 115-119.

19 Zum Verhältnis von Ps 2 und 110 vgl. Körting 2006, 196-219. 
vorhandenen, wenn vielleicht auch nur fragmentarisch erhaltenen Grundtextes aus vorexilischer Zeit kommen philologische und semantische Hürden hinzu, so dass schon die Übersetzung an manchen Stellen unsicher ist ${ }^{20}$.

(1a) [Ein Davidslied. Ein Psalm.]

(1b) Spruch Jhwhs zu meinem Herrn:

(1c) „Setze dich (auf den Thron) zu meiner Rechten,

(1d) bis ich deine Feinde mache

(1e) zum Schemel deiner Füße.“

(2a) Das Zepter deiner Macht wird Jhwh ausstrecken vom Zion:

(2b) „Herrsche inmitten deiner Feinde!“

(3a) [Dein Volk ist willig am Tag deiner Heeresmacht (MT) /

Bei dir ist Hoheit am Tag deiner Macht (LXX).]

(3b) „In heiliger Pracht aus dem Mutterschoß,

(3c) aus dem Morgenrot ist dir Tau: Ich habe dich geboren.“

(4a) [Jhwh hat geschworen, und es gereut ihn nicht:

(4b) „Du bist Priester in Ewigkeit nach der Weise Melchisedeks.“]

(5a) Mein Herr (der König) ist zu deiner (Jhwhs) Rechten,

(5b) er hat am Tag seines Zorns Könige zerschlagen.

(6a) [Er hält Gericht unter den Völkern, Leichen die Fülle,

(6b) er zerschlägt Häupter weit über die Erde hin.]

(7a) Aus dem Bachtal am Weg trinkt er (der König),

(7b) deshalb erhebt er das Haupt (MT) /

deshalb wird er (Jhwh) das Haupt (des Königs) erhöhen (LXX).

Mit einer gewissen Wahrscheinlichkeit wird man in Vers 1a.3a.4.6 literarische Aktualisierungen einer Grundfassung annehmen dürfen. Diese ist als dreistrophiger Psalm mit je zwei Bikola in Vers 1b-2.3b-c.5.7 erhalten. Die motivische Nähe der Grundfassung zum rekonstruierten vorexilischen Bestand von Ps 2 ist mit Händen zu greifen. Die sessio ad dexteram in Ps 110,1b-e ist der Einsetzung des Königs durch den Himmelsthroner in Ps 2,6 nahe; identisch sind der Aufruhr der Feinde, die Vorstellung von der Einsetzung des Herrschers als göttliche Geburt und der Zion als Ort des Geschehens. Als deutlichster Unterschied zwischen den - soweit erkennbar - vorexilischen Grundfassungen von Ps 2 und 110 fällt auf, dass der in Ps 110 zur Rechten Jhwhs inthronisierte Herrscher nie melek

$20 \mathrm{Zu}$ Ps 110 vgl. die unterschiedlichen Analysen von Saur 2004, 205-224; Hossfeld/Zenger 2008, 195-216; von Nordheim 2008, 5-141; Granerød 2010, 174-246; Feldmeier/Spieckermann 2018, 94-99. 
„König“, sondern ’ădōnî „mein Herr“ genannt wird. Ps 110,1b und Vers 5a bilden ein enges Paar - wie in Ps 2 der Himmelsthroner, der auch „Herr“ genannt wird (V.4), und „mein König“ als der auf dem Zion eingesetzte Sohn Gottes. Diese Nähe wird in Ps 110 durch die Eingangszeile Vers 1bc noch einmal verdichtet. Jhwh gewährt „meinem Herrn“ - wie der das Ritual leitende Priester in stellvertretender Mittlerfunktion für alle im Tempel Anwesenden sagt - ein Orakel: „Throne zu meiner Rechten“. „Meine Rechte“ ist der Topos größter, von Gott gewährter Nähe. Zusammen mit dem gemeinsamen Gebrauch des Titels 'dny - schon in nachexilischer Zeit gern neben und anstelle des göttlichen Eigennamens Jhwh gestellt und später von den Masoreten mit dem Qere perpetuum 'ădōnāy „Herr“ versehen, um es von ’ădōn̂̂ „mein Herr“ als Titel für Könige und andere Personen von Stand zu unterscheiden - ist die Gottesnähe zwischen Jhwh und „meinem Herrn“ nicht zu überbieten. Demgegenüber sind die Feinde selbstverständlich Könige, die es zu beherrschen gilt. Ist Ps 110 auch zweifellos ein Ritualtext mit Wurzeln in der vorexilischen Gott-König-Theologie, macht er aller Wahrscheinlichkeit nach von dem Titel melek „König“ für Jhwh und den Herrscher zu seiner Rechten bewusst keinen Gebrauch, um den Titel allein für die zu reservieren, die der Herrschaft der beiden widerstehen.

In der vorexilischen Fassung ist in Ps 110 folgender ritualisierter Sprechakt zu erkennen: Ein hochgestellter Priester spricht in Vers 1b-e dem im Tempel anwesenden König, angeredet als 'ădōnî „mein Herr“, ein Jhwh-Orakel zu. Die Aufforderung, der König möge zu Jhwhs Rechten seinen Thronsitz einnehmen (yšb), ist im Alten Testament singulär. Hat Ps 110 im Judentum schon seit der hellenistischen Zeit eine beachtliche Wirkungsgeschichte gehabt, ist speziell die Rezeption der sessio ad dexteram im Neuen Testament beispiellos ${ }^{21} . \mathrm{Zu}$ ihrer alttestamentlichen Kontextualisierung bietet sich am ehesten die Einsetzung des Königs auf dem heiligen Berg Zion durch den Himmelsthroner und Herrn ('ădōnāy) in Ps 2,4-6 an. Legte sich in Ps 2 auf Grund der Topoi Himmel und Zion prima facie der Gedanke eines Sphärenwechsels Gottes im Sinne einer Katabasis nahe, könnte man parallel erwägen, die Aufforderung zur sessio ad dexteram an „meinen Herrn“ in Ps 110 als eine Anabasis des Königs in die himmlische Gottesnähe zu deuten. Aber ein Sphärenwechsel wird in Ps 110 so wenig inszeniert wie in Ps 2. Jhwh will in Ps 110,1de dem zu seiner Rechten Thronenden die Feinde gewiss nicht im Himmel zu Füßen legen. Der Himmel wird in Ps 110 überhaupt nicht genannt. Ist der himmlische Raum auch hier nicht kategorisch auszuschließen, erübrigt sich seine Erwähnung aus dem Grund, dass als Ort des

21 Zur jüdischen Rezeption vgl. von Nordheim 2008, 171-298; zur neutestamentlichen Rezeption vgl. den Beitrag von Feldmeier in diesem Band. 
rituellen Geschehens der Zion im Zentrum steht (V. 2a). Hier findet das Ritual statt und hier ist Jhwh anwesend, um selbst das Zepter der Macht des Königs auszustrecken, damit er über die Feinde herrschen kann (V. 2b). Wieder sind die beiden Akteure so unzertrennlich beieinander wie bei der sessio ad dexteram. Die beiden agieren ununterscheidbar einmütig und spiegeln damit die Nähe wider, die Tempel und Palast auf dem Zion in vorexilischer Zeit gehabt haben. Wahrscheinlich hat der König im Ersten Tempel seinen festen, offiziellen Platz gehabt (vgl. 2Kön 23,3a) ${ }^{22}$. Der einzige Topos, der in Ps 110 genannt wird, ist Zion, also der Ort, der in vorexilischer Zeit für das Bei- und Ineinander von Tempel und Palast, von Gottkönigtum und davidischer Dynastie steht. Jhwh und der sprechende Priester sagen dem „Herrn“ unisono die Herrschaft „inmitten der Feinde“ zu (V. 2b), weil sie „der Schemel deiner Füße“ sind (V. 1e), hier ein Requisit der Macht des Königs, welches normalerweise der Königsmacht Gottes vorbehalten ist (Jes 66,1; Ps 99,5; 132,7; 1Chr 28,2) ${ }^{23}$. Entsprechende Szenen sind in der ägyptischen Ikonographie gut belegt ${ }^{24}$.

Die Nähe von Ps 2 und 110 ist auch in Ps 110,3bc zu beobachten. Geht der Kampfgemeinschaft von Jhwh und König in Ps 2,7bc die mit der Metapher der Geburt gesagte Gewährung des Vater-Sohn-Verhältnisses voraus, folgt dieselbe Metapher in Ps 110,3bc, angereichert durch weitere Anspielungen auf einen umfassenderen mythischen Kontext, die aber in der im Psalm präsentierten Sequenz gleichwohl nur begrenzt verständlich sind ${ }^{25}$. Auf dem Hintergrund von Ps 2,7c und mit der Septuaginta ist die Geburtsmetapher auch in Ps 110,3c an-

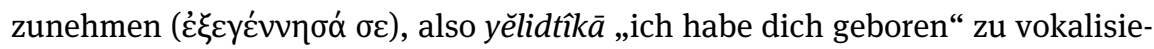
ren, und nicht yaldūtêkā „deine Jugend“, wie es der Masoretische Text bietet.

22 Demgemäß agiert beim Bundesschluss in der vorexilischen Fassung von 2Kön 23,3 allein der König vor Jhwh an einem bestimmten Ort im Tempel, nicht das Volk (vgl. Spieckermann 2013, 332-335).

23 In dem (nach)exilischen Text Lam 2,1 ist Zion Jhwhs Schemel der Füße, den er vom Himmel zur Erde geschleudert hat. Dies ist Zions Katabasis im Gericht. Sie erweist noch einmal ex negativo, dass Zion und Himmel jenseits dieser Katastrophe nicht zu scheiden sind.

24 Dies gilt für die sessio ad dexteram, für das Gott-Sohn-Verhältnis und für die Feinde als Schemel der Füße; vgl. die Beispiele bei Keel ${ }^{3} 1980$, 230-233.240 f.

25 Ps 110,3a fügt sich kaum in den Parallelismus membrorum ein und ist auch vom Inhalt her gegenüber dem Kontext schwierig. Wahrscheinlich ist V. 3a später eingefügt worden, weil der Einsatz des Volkes beim Kampf gegen die Feinde vermisst worden ist. So wenig das Volk in vorexilischen Psalmen bei Jhwhs und des Königs Kämpfen eine Rolle spielt, so wenig ist sein Fehlen in nachexilischer Zeit vermittelbar. Freilich ist in V. 3a unsicher, ob überhaupt 'ammĕkā

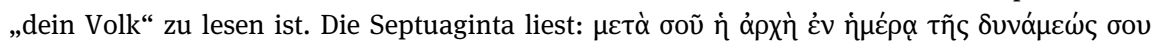
„Bei dir ( ¿imkā) ist Herrschaft/Hoheit (nědibōt) am Tag deiner Macht.“ Es ist schwer zu entscheiden, welche der beiden Lesarten die lectio difficilior ist. 
Die heilige Pracht in Ps 110,3b ist in fast identischer Form in Ps 29,2 zu finden und signalisiert ein Geschehen in den oberen Rängen unter Beteiligung des göttlichen Hofstaates ${ }^{26}$. In diese Richtung weisen auch die drei folgenden Nomina in Ps 110,3bc: reḥem „Mutterleib, Mutterschoß“, šaḥar „Morgenröte“ “27, țal „Tau“. Die oben vorgeschlagene Übersetzung in Treue zum Masoretischen Konsonantentext versteht die Anspielungen auf den Mutterleib, die Morgenröte und den Tau als Vorbereitung und Hinführung auf Gottes entscheidende Tat, die Geburt des königlichen Gottessohnes, der hier im Unterschied zu Ps 2 weder König noch Sohn genannt wird. Die Septuaginta bietet für dieses Verständnis eine Stütze, obwohl sie hier nicht in jeder Hinsicht den ursprünglichen Text repräsentiert. Sie verbindet die ersten beiden Worte běhadrê qōdeš mit Vers 3a:

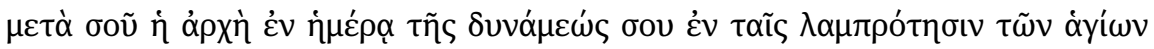
„Mit dir ist die Herrschaft am Tage deiner Macht im Glanz der Heiligen.“ Dann

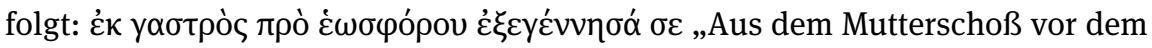
Morgenstern habe ich dich hervorgebracht. “28 Zwar bietet die Septuaginta eine andere mythische Anspielung als der hebräische Konsonantentext von Ps $110,3 \mathrm{bc}$, doch beide Varianten betreiben die Mythisierung des Geschehens entschlossener als der von den Masoreten punktierte Text ${ }^{29}$. Dies legt sich durch die Beobachtung nahe, dass die drei hebräischen Nomina rehem „Mutterleib, Mutterschoß“, šahar „Morgenröte“ und țal „Tau“ in der aus Ugarit bekannten altsyrischen Mythologie allesamt Namen von Gottheiten sind: rḥmy Rahmay „Mut-

26 Zugleich verwundert es nicht, dass Hieronymus in der Vulgata iuxta Hebraicum anstelle von běhadrê qōdeš der Lesung běharěrê qōdeš „auf den heiligen Bergen“ den Vorzug gegeben hat. Gegenüber Ps 29 wird hier also Ps 2 als Referenztext präferiert, wo es ebenfalls um die Geburt des königlichen Gottessohnes geht.

27 Der Masoretische Text bietet mišh̆ār, welches ein Hapaxlegomenon mit identischer Bedeutung anstelle des gut belegten šahar „Morgenröte“ wäre. Wahrscheinlich muss man den Konsonantentext gegen die Masoreten umvokalisieren: miššahar „aus der Morgenröte“, parallel zu „aus dem (Mutter-)Schoß“.

28 Hieronymus übersetzt Ps 110(109),3 iuxta Septuaginta: tecum principium in die virtutis tuae in splendoribus sanctorum ex utero ante luciferum genui te, während er iuxta Hebraicum sowohl der hebräischen Vorlage als auch der Verständlichkeit bei den christlichen Lesern Rechnung zu tragen sucht: populi tui spontanei erunt in die fortitudinis tuae / in montibus sanctis quasi de vulva orietur tibi ros adulescentiae tuae. Das „Zepter deiner Macht“ in V. 2 gibt Hieronymus beide Male mit virga (virtutis tuae / fortitudinis tuae) wieder. Ob die Nähe von virga „Zweig, (dünner) Stab“ und ros „Tau“ wegen der Assonanz an Jes 11,1 virga de radice Iesse et flos de radice eius beabsichtigt ist? Hieronymus hat hier wahrscheinlich die Vernetzung von Ps 110(109) mit prophetischen Verheißungen im Blick gehabt.

29 Zu Ps 110,3 vgl. Grohmann 2007, 93-117. 
terschoß“, eine der Athirat, Gattin des Hochgottes El, assoziierte Göttin ${ }^{30}$, šhr Šahar „Morgenrot“, fast immer zusammen mit šlm Šalim „Abendrot“, Söhne des $\mathrm{El}^{31}$, und țly Ṭallayu „Tau“, regelmäßig zusammen mit Pidrayu und Arșayu, Frauen und „Töchter“ des Baal, alle drei Erscheinungsformen des Niederschlags, nicht personifiziert auch dem Licht, dem Himmel und den Sternen verbunden $^{32}$. Hier muss zudem auf Jes 26,16-19 hingewiesen werden. Es handelt sich um einen zur spätnachexilischen Jesaja-Apokalypse Jes 24-27 gehörigen Text, der in einem an Jhwh gerichteten Wort das Eingeständnis einer WirGruppe enthält, dass ihre Wehen und ihre Geburt nur wertlosen Wind erzeugen und deshalb keine Rettung bewirken können. Demgegenüber ist Jhwh in der Lage, den Toten wieder neues Leben zu schenken. Mit der Auferstehung und Auferweckung wird für das von Gott neu geschenkte Leben die Metapher țal 'ôrôt „der Tau der Lichter“ verbunden. Parallel dazu steht in Jes 26,19 die Metapher von der die Toten gebärenden Unterwelt, die freilich diesen Hilfsdienst nur vollbringen kann, weil Jhwh seine Toten schon vorher zu neuem Leben erweckt hat. Auf Grund von Jes 26,19 wird man erwägen dürfen, ob nicht der Tau als Metapher des Lebens auch schon in Ps 110,3bc bekannt gewesen sein könnte. Die Gabe des Lebens gewährt Jhwh mit Hilfe mythischer Wesen, um dann selbst den Herrscher seiner besonderen Nähe zu gebären.

Trotz aller Unsicherheit der Deutung im Detail ist offenkundig, dass in Ps 110,3bc die dem königlichen Herrscher von Gott zugesprochene sessio ad dexteram durch mythisch aufgeladene Geburtsmetaphorik nachhaltig unterstützt wird. Gegenüber der knappen, geschliffenen Formulierung in Ps 2,7bc scheint in Ps 110,3bc ein älteres Stadium bezeugt zu sein, das spätere Tradenten

30 Vgl. KTU/CAT 1.23,16, wahrscheinlich auch (ohne ,y am Schluss) 1.23.13; vgl. Smith 2006, 50-61.

31 Vgl. KTU/CAT 1.23,49-54; vgl. Smith 2006, 95-103; Šaḥar und Šalim sind in Personennamen auch je für sich als theophores Element belegt, vgl. del Olmo Lete / Sanmartín ²004, 64-65 sub voce ilsḥr und ilšlm.

Es mag von Ps 110 auch eine mythische Querverbindung zu dem Sturz von Hêlēl ben-šaḥar

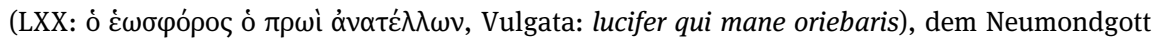
Helel, Sohn des Morgenrots, in Jes 14,12 bestehen. Im ugaritischen Epos über den König Aqhatu hat der Neumondgott Hilalu Töchter, die k $k$ trt kațarātu sind, Geburtshelferinnen (KTU/CAT 1.17 II,26-27; vgl. Niehr 2015, 277; del Olmo Lete / Sanmartín 22004, 472 sub voce kțrt). So hat unter den mythischen Vorläufern von Ps 110 auch das Morgenrot eine Verbindung zum Geburtsgeschehen.

32 Vgl. KTU 1.3 I,22-27; III,5-8 (und schon vorher II,38-41); IV,47-53; V,38-43; 1.4 I,9-18; IV,5057; VI,7-11; 1.5 V,10-11; vgl. del Olmo Lete / Sanmartín 22004, 108 sub voce arșy; 663 sub voce pdr (II) und pdry; 889 sub voce țl und țly; zu den Göttinnen vgl. ferner Watson 1993, 47-59; Smith/Pitard 2009, 115-121. 
in theologische Bedenken gestürzt hat. Die intendierte Nähe zwischen Jhwh und König ist in der rekonstruierten Grundfassung von Ps 110 so groß gewesen, dass die doppelte Möglichkeit, welcher 'ādôn „Herr“- ob Jhwh oder der König agiert, bewusst gewagt worden ist. So ist es bereits in der unauflöslich engen Herrschaftsausübung der beiden in Vers 2, und so verhält es sich noch einmal in Vers 5, der in der Grundfassung unmittelbar auf Vers 3bc gefolgt ist. Eigentlich ist es Jhwhs Aufgabe, am Tag seines Zorns Könige oder andere Feinde zu zerschmettern. Ganz in diesem Sinne ergeht die Drohung gegen die Herrscher in der vorfindlichen nachexilischen Fassung von Ps 2,10-12. Genau in diesem Sinne haben die Masoreten dann auch Ps 110,5 vokalisiert: 'ădōnāy „HERR“ für Jhwh statt 'ădōnî „mein Herr“ für den Davididen. Dieses Verständnis ist jedoch zu ihrer Zeit schon gut tausend Jahre alt, denn es ist bereits in der Septuaginta

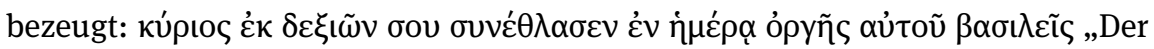
Herr von deiner Rechten aus hat Könige am Tage seines Zorns zerschmettert“ (Ps 109,5 LXX) ${ }^{33}$. Folglich ist es auch in 109,6 LXX Gott, der Gericht unter den Völkern hält und deren Haupt zerschmettert, um dann abschließend in 109,7 LXX seinem König, an dessen Rechte er weilt und der aus einem Bachtal (naḥal, $\chi \varepsilon i ́ \mu \alpha \rho о \varsigma)$ trinkt, zu verheißen, dass er sein Haupt erheben wird. In der dritten Strophe von Ps 109 LXX tut alles Entscheidende Gott selbst - genau wie in der Abschlussstrophe von Ps 2 (V. 10-12).

Die sich in Ps 110 (109 LXX) einstellende Irritation, dass der König zwar in Vers 1 zur Rechten Jhwhs thront, Jhwh aber in Vers 5 an der Rechten des Königs ist und die aufständischen Könige zerschmettert, haben Septuaginta und Masoreten in Kauf genommen, weil für sie Jhwhs Handeln gegenüber dem des inthronisierten Königs im ganzen Psalm die Priorität haben soll. Diese Intention ist aus der Rezeptionsperspektive der königlosen Zeit seit 587/6 v. Chr. gut verständlich. Wie bereits bei der Auslegung von Vers 1-3* deutlich geworden ist, verfolgt die vorexilische Fassung von Ps 110 ein anderes Ziel: die Akzentuierung der unauflöslichen Nähe von Jhwh und dem zu seiner Rechten inthronisierten König. Der unpunktierte hebräische Text stimmt mit dieser Intention auch in Vers 5 völlig überein. Im unmittelbaren Anschluss an die vorexilische Fassung von Vers 1-3* gelesen, verlangt Vers 5 die Deutung, dass der als Herr angeredete König, der nun „zu deiner (= Jhwhs) Rechten“ thront, am Tag seines (= des Königs) Zorns feindliche Könige zerschmettert hat. Jhwh und der König zu seiner Rechten sind weiterhin in ihrem Handeln unzertrennlich. Sind Vers $1-3^{\star}$ wahrscheinlich von einem Priester im Tempel zum anwesenden König als JhwhOrakel gesprochen worden, redet derselbe Priester in Vers 5 zwar Jhwh an, sagt

33 Auch die Vulgata folgt in beiden Versionen diesem Verständnis. 
aber in Vers 5 und 7 keinem anderen als dem König die Antizipation des Sieges über die Feinde $\mathrm{zu}^{34}$. Dieser Akt unterstreicht noch einmal die durch die sessio ad dexteram dem König gewährte Gottesnähe. In diesem Licht ist auch der abschließende Vers 7 zu verstehen. Der König trinkt nach der Schlacht nicht aus einem Fluss (nāhār), sondern aus einem Wadi oder Bachtal (nahal), also aus einem perennierenden oder intermittierenden Wasserlauf. Hier ist allerdings impliziert, dass dieser nahal Wasser in Fülle führt. Sonst könnte der König nicht „am Weg“ daraus trinken. Das gefüllte Wadi ist hier nicht Bild der Gefahr, sondern des Überflusses, welcher Fruchtbarkeit und Wohlstand verspricht. Es passt zusammen mit tal „Tau“ in Vers 3c, welcher in der altsyrischen Mythologie als țly Tallayu „Tau“ zusammen mit Pidrayu und Arșayu zu Baals Entourage als Göttinnen des Niederschlags und Gedeihens zählt. Wenn der König anschließend sein Haupt erhebt, ist dies Erweis seiner Macht, nachdem er Könige zerschmettert hat ${ }^{35}$. Seine Haupterhebung durch Gott ist hier die später eingetragene Lesart. Ursprünglich erhebt der König sein eigenes Haupt. Alles ist bei diesem König präsent, was zur gelingenden Herrschaft gehört: die Inthronisation in unüberbietbarer Gottesnähe, die Herrschaft über die feindlichen Könige und Wasser in Fülle als Voraussetzung für Fruchtbarkeit und Wohlstand im Lande.

Es verwundert nicht, dass die exzeptionelle Nähe von Jhwh und König im Anschluss an die Geburtsvorstellung in Ps 110,3bc noch für eine weitere entscheidende Akzentverlagerung in nachexilischer Zeit genutzt worden ist: die Wandlung des zur Rechten Jhwhs installierten Königs in einen auf ewig bestell-

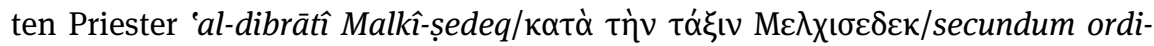
nem Melchisedech „nach der Weise Melchisedeks“. In vorexilischen Texten des Alten Testaments wäre dies ein undenkbarer Ämtertausch. Melchisedek ist als Priester-König von Salem bekannt, der dem Segensmittler Abraham nach seinem Sieg über mächtige Könige und die damit verbundene Befreiung Lots in Gen 14,18-20, einem Text aus fortgeschrittener nachexilischer Zeit, Segen aus der Stadt zuteil werden lässt, die später einmal Jerusalem heißen und Zentrum des Judentums sowie Fluchtpunkt großer Erwartung sein wird. Melchisedeks Verbindung mit Abraham, seine Doppelfunktion als Priester und König und

34 Das Gericht über die Völker, welches in V. 6 unter sprachlichen Anleihen im Kontext formuliert wird, ist mit hoher Wahrscheinlichkeit ein Nachtrag, für den nur Jhwh als handelndes Subjekt in Frage kommt - dann natürlich nicht nur in V. 6, sondern wie in der späteren Rezeption in V. 5-7 insgesamt (vgl. 1 Sam 2,10; Jes 3,13; Ps 7,9; 9,9; 96,10.13; 98,9 et al.).

35 Der Duktus des Textes legt nicht nahe, dass der König aus dem Wadi das Blut der besiegten Könige trinkt; zu dieser Deutung vgl. Becker 1986, 17-31. 
schließlich die Bedeutung des Namens Malkî-ședeq „Mein König ist (die Gottheit) Ședeq/Gerechtigkeit“ macht diese Gestalt für den Ergänzer in Ps 110,4 so attraktiv. Denn dass es sich bei diesem Vers um einen Nachtrag handelt, der bereits in Kenntnis von Gen 14 vorgenommen worden ist, leidet keinen Zweifel. Man kann nur auf einen neuen Priester „nach der Weise Melchisedeks“ hoffen ${ }^{36}$, wenn man dafür einen Anhaltspunkt hat, nämlich Gen 14,18-20.

Ps 110,4 will den vorexilischen Königspsalm in königloser Zeit zum Hoffnungstext auf ein neues Priestertum machen, das eine Symbiose priesterlicher und königlicher Tradition nicht nach bekannten Vorbildern aus staatlicher Zeit, sondern in Anknüpfung an die nachexilische entworfene Gründerzeit wagt, wo Abraham und Salem durch den Priester-König Melchisedek das erste Mal in Kontakt gekommen sind. Wem Jhwh die Nähe der sessio ad dexteram nach der Weise Melchisedeks neu gewähren wird, konkretisiert dieser Ergänzer von Ps 110 nicht. Der in der Überschrift Vers 1a genannte David mag die Erwartung beeinflussen, aber er prägt sie nicht, denn der erwartete Priester-König lenkt die Hoffnung in eine Richtung, die geschichtlich nicht realisiert worden ist. Die Hochschätzung des aaronitischen Hohepriestertums bei Jesus Sirach basiert auf der Priesterschrift, nicht zuletzt aber auch auf Ps 110. Denn Jhwh erhöht (wyrm,

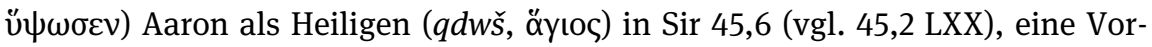
stellung, die sehr wahrscheinlich auf der nachexilischen Lesart von Ps 110,7, der Haupterhebung des Königs durch Jhwh, beruht.

In Qumran hat der geschichtlich nicht belastete Priester-König Melchisedek Hoffnungen beflügelt, die in ihm nach Ausweis des Midrasch zu Melchisedek (11Q13) den endzeitlichen Richter und Befreier erwarten, der die rettet, die zu seinem Erbe und Los gehören (II,5.8) ${ }^{37}$. In allegorischer Auslegung von Jes 52,7 „Wie lieblich sind die Schritte des Freudenboten auf den Bergen, der Frieden verkündet, der gute Botschaft bringt, der Rettung verkündet, der zu Zion spricht: Dein Gott ist König geworden!“ - werden die Berge zu Propheten (hnby'y[m]), der Freudenbote (hmbśr) zum Gesalbten des Geistes (mšyḥ hrw[h], vgl. Lk 4,18; Apg 10,38), der Bringer guter Botschaft zum Unterweiser in allen Weltzeiten (l[h]śkylmh bkwl qșy $\left.h^{e}[w l m]\right)$, Zion wahrscheinlich zur Versammlung aller Söhne der Gerechtigkeit, die den Bund aufrichten (mqym[y] hbryt) und „dein Gott“ zu Melchisedek, der die Söhne retten wird aus der Macht des Belial

36 Die Komposit-Präposition 'al-dibrat(î) mit der Bedeutung „nach der Weise, nach der Ordnung, in Ansehung von“ (vgl. Gesenius/Donner ${ }^{18} 2013$, 241a sub voce dibrâ ${ }^{*}$ ) ist nur noch in Koh 3,18; 7,14 und 8,2 belegt. Wahrscheinlich handelt es sich um eine jüngere Variante von 'alděbar (vgl. Gesenius/Donner ${ }^{18} 2013$, 240b sub voce dābār II 6).

37 García Martínez / Tigchelaar 1997, 1206-1209; Steudel 2001, 175-185. 
([yṣy]l[mh my]d bly'l, II,15-25), der mythischen Personifikation des Bösen. Von Melchisedek ist vorher schon mit den Worten von Ps 82,1 gesagt worden: „Elohim steht in der Versammlung Gottes, mitten unter den Göttern richtet er“ $(\mathrm{II}, 10)^{38}$. Größeres kann man von ihm kaum sagen. Ohne die sessio ad dexteram in Ps 110 wäre diese kühne Identifikation kaum denkbar gewesen ${ }^{39}$.

\section{Erflehter und gewährter Sphärenwechsel in nachexilischen Psalmen}

Die zuletzt behandelten Texte aus dem Sirachbuch und Qumran greifen bereits weit in die nachexilische Zeit aus. Ihnen gehen Texte aus den königlosen Jahrhunderten seit dem Fall Jerusalems im Jahre 587/6 v. Chr. voran, die die Verwüstung des Jerusalemer Tempels und der Stadt sowie den desolaten Zustand des Volkes bitter beklagen. Durch den Verlust von Tempel und Königtum als zentralen Mittlerinstanzen, wie sie in Ps 2 und 110 Gestalt gewonnen haben, hat diese göttliches und menschliches Handeln umfassende und verbindende Sphäre ihr Zentrum verloren: Zion, die Stätte des sichtbaren Miteinanders von Tempel und Palast und zugleich des theologisch konzentrierten Ineinanders göttlicher und königlicher Präsenz. Durch den Verlust dieses Zentrums klaffen die Sphären göttlicher Präsenz und menschlichen Ergehens, vor allem Erleidens, auseinander. In Klagetexten, die diese Situation zu Wort bringen, wird der Himmel zum Refugium Gottes, welches ihn vom Geschehen auf Erden distanziert und für die Leidenden schwer zugänglich macht. Das große Klagegebet Jes 63,7-64,11 spitzt das Problem in manchen, an Schärfe kaum zu überbietenden Formulierungen $\mathrm{zu}^{40}$.

38 Sehr suggestiv ist auch der in II,9-41 kombinierte Bezug auf Ps 82,2 und 7,8-9, weil Jhwhs Zurückkehren zur Höhe und das damit verbundene Völkergericht - in Ps 7,8-9 kompliziert formuliert und damit eine erhebliche exegetische Herausforderung - auf Melchisedek gedeutet wird. Zunächst werden die $q d w s ̌ y ~ ' l$ „Heiligen Gottes“ zu Richtern erhöht (Ps 82,2). Und über diese ' $d t$ ' $l$ „Gottesversammlung“ soll dann Melchisedek lmrwm „zur Höhe“ zurückkehren. Unter seiner Herrschaft wird aus dem Völkergericht eine Rettungstat für die, die in der Gewalt Belials sind. Wer zu den Geretteten gehört, wird nicht genau gesagt. Die Anabasis Melchisedeks setzt zwingend die nicht erwähnte Katabasis voraus. Nimmt man hier vielleicht an der Genese einer eschatologischen Rettergestalt teil, zu deren Wirken Katabasis und Anabasis gehören?

39 Vgl. Steudel 1994, 182-185.

40 Zum ganzen Gebet vgl. die Analyse von Wilke 2014, 108-139 und die konzentrierte theologische Auslegung von Braulik 2018, 1-18. 
(63,15a) Blick vom Himmel herab und sieh

(15b) aus deiner heiligen und herrlichen Wohnung!

(15c) Wo sind dein Eifer und deine Macht,

(15d) deine innere Teilnahme (hămôn mēêêā)?

(15e) Dein Erbarmen halte sich nicht zurück ('al-yit'appěqû),

(16a) denn du bist unser Vater.

(16b) Denn Abraham kennt uns nicht,

(16c) und Israel (sc. Jakob) weiß nicht um uns.

(16d) Du, Jhwh, bist unser Vater,

(16e) unser Erlöser ist von Ewigkeit her dein Name.

(19a) Wir sind (solche) geworden, über die du von Ewigkeit her nicht geherrscht hast,

(19b) über die dein Name nicht genannt worden ist.

(19c) Ach, dass du den Himmel zerrissest, herabstiegst,

(19d) Berge vor dir erbebten!

…

(64,7a) Nun aber, Jhwh,

(7b) du bist unser Vater.

(7c) Wir sind der Ton, und du bist unser Schöpfer,

(7d) Werk deiner Hände sind wir alle.

(8a) Zürne nicht, Jhwh, über die Maßen

(8b) und gedenke nicht auf ewig der Schuld!

(8c) Sieh, schau doch, dein Volk sind wir alle.

(9a) Deine heiligen Städte sind zur Wüste geworden.

(9b) Zion ist Wüste,

(9c) Jerusalem Einöde geworden.

(10a) Unser heiliger und herrlicher Tempel,

(10b) wo unsere Väter dich gepriesen haben,

(10c) ist zum Fraß des Feuers geworden,

(10d) und alles, was uns kostbar war, liegt in Trümmern.

(11a) Willst du trotz allem dich zurückhalten, Jhwh,

(11b) schweigen und uns ganz und gar erniedrigen?

Im Alten Testament wird Gott nur in diesem Text dreimal „unser Vater" genannt (Jes 63,16; 64,7). Die Bitten, die hier an ihn ergehen, sind besonderer Art. Sie sind nicht vom Vertrauen der Bittenden geprägt, dass sie erhört werden. Vielmehr hat die Anrede „unser Vater“ einen flehenden, anklagenden Ton, weil Gott die vom Vater erwartete Nähe und sein gerade mit dem Vaternamen verbundenes Erbarmen (vgl. Ps 103,13) vermissen lässt (Jes 63,15e.16a). Der Himmel als Ort göttlicher Gegenwart ist nicht länger auf Zion für die Seinen erfahrbar, vielmehr ist Zion-Jerusalem zur Wüste und der Himmel als Gottes herrschaftlicher Palast (Jes 63,15ab) zum unerreichbaren Ort des Rückzugs geworden, eine von Gott selbst getroffene Wahl, die nur er durch sein Hinabschauen vom Himmel zu revidieren vermag. 
Diese Entscheidung wird im Gebet dringlich gemacht, denn die Mittlerinstanzen der vorexilischen Zeit sind im Strudel der Vernichtung - Folge von Gottes Zorn - untergegangen. Es verdient Beachtung, dass der Untergang des davidischen Königtums und des priesterlichen Tempeldienstes in dieser Klage mit keinem Wort erwähnt werden. Möglicherweise ist die theologische Auseinandersetzung um den Verlust der vorexilischen Mittlerinstanzen schon eine Weile im Gange ${ }^{41}$. Jes 63,7-64,11 verschärft die Forderung nach Gottes eigenem Handeln dadurch, dass selbst die entscheidenden Vätergestalten der mythischen Gründungsgeschichte Israels - Abraham und der bewusst mit dem Namen Israel benannte Jakob $(63,16 b c)$ - nicht als Ersatz für das verlorene Königtum ins Feld geführt werden können ${ }^{42}$. Gott selbst muss die gewählte Isolation in den oberen Sphären beenden, indem er den unzugänglichen Himmel zerreißt. Göttliche Herrschaft kann allein dadurch wieder evident werden, dass sich Jhwh als Erlöser erweist, wie Jes 63,16e im Bezug auf deuterojesajanische Theologie formuliert (vgl. Jes 41,14; 43,1.14; 44,6.22-24; gō'ălēnû „unser Erlöser“ in 47,4).

Wenn es um die Ablehnung von Orten und Personen als Mittlerinstanzen geht, ist die Klage in Jes 63,7-64,11 von nachgerade provokativer Deutlichkeit. Berge dürfen erbeben (63,19d) als Erweis von Gottes erneutem Handeln, aber sie kommen als Ort von Gottes Präsenz nicht in Frage. Zion und Jerusalem sind zwar Gottes „heilige Städte“, nun aber zur Wüste geworden $(64,9)$ und „unser heiliger und herrlicher Tempel“ eine Trümmerstätte $(64,10)$. Bewusst bildet dieses Ensemble den Kontrast zu Gottes „heiligem und herrlichem Palast“ im fernen Himmel (63,15ab). Nichts kann Gottes eigene erlösende Gegenwart mehr ersetzen. Oder will er wirklich das Werk der Erniedrigung seines Volkes weiter fortsetzen? Mit dieser Frage in Jes 64,11 schließt das Gebet an „unseren Vater“. Es fordert Gottes Sphärenwechsel im Sinne seiner Wandlung vom fernen zum nahen, vom zürnenden zum erlösenden Gott mit letztem Nachdruck ein.

Ps 80 in der Endfassung scheint Jes 63,7-64,11 zu kennen. Jedenfalls kann man dies auf Grund der identischen Bitte an Gott, vom Himmel herabzublicken (Jes 63,15a = Ps 80,15b), mit Grund erwägen. Diese Vermutung wird ferner durch die Beobachtung unterstützt, dass die Aufforderung an Jhwh, seine Hand möge über dem Mann seiner Rechten sein (Ps 80,18a), wohl eine Anspielung auf die sessio ad dexteram in Ps 110,1 ist.

$41 \mathrm{Zu}$ diesem Problem vgl. Feldmeier/Spieckermann 2018, 75-83.

42 Auch auf diesem Hintergrund wird noch einmal deutlich, wie jung der Nachtrag in Ps 110,4 sein muss, der den König zu Jhwhs Rechten mit dem König und Priester Melchisedek identifiziert, der einst Abraham in Gen 14,18-20 gesegnet hat. 
(2a) Du, Hirte Israels, höre,

(2b) der du Joseph leitest wie eine Herde,

(2c) der du über den Keruben thronst, erstrahle

(3a) vor Ephraim, Benjamin und Manasse!

(3b) Erwecke deine Macht

(3c) und komm - uns zur Rettung!

(4a) ,Jhwh', stelle uns wieder her,

(4b) lass dein Angesicht leuchten, dann sind wir gerettet!

(5a) Jhwh [Gott] Zebaoth,

(5b) wie lange noch raucht (dein Zorn) beim Gebet deines Volkes?

(6a) Du hast sie mit Tränenbrot gespeist

(6b) und mit Tränen getränkt über die Maßen.

(7a) Du machst uns zum Gezänk unserer Nachbarn,

(7b) und unsere Feinde treiben ihren Spott.

(8a),Jhwh'Zebaoth, stelle uns wieder her,

(8b) lass dein Angesicht leuchten, dann sind wir gerettet!

(9a)Einen Weinstock aus Ägypten hast du ausgehoben,

(9b) hast Völker vertrieben und ihn eingepflanzt.

(10a) Raum hast du ihm geschaffen,

(10b) er konnte seine Wurzeln schlagen und das Land füllen.

(11a) Berge wurden bedeckt von seinem Schatten,

(11b) von seinen Ranken die Zedern Gottes.

(12a) Seine Triebe hat er ausgestreckt bis ans Meer

(12b) und bis zum Strom seine Schösslinge.

(13a) Warum hast du seine Mauern eingerissen,

(13b) so dass alle, die des Weges kommen, von ihm pflücken?

(14a) Der Eber aus dem Wald wühlt ihn um,

(14b) und wilde Tiere weiden ihn ab.

(15a),Jhwh`Zebaoth, kehre doch um,

(15b) blick vom Himmel herab und sieh!

(15c)Nimm dich dieses Weinstocks an,

(16a) und stärke ihn ${ }^{43}$, den deine Rechte gepflanzt

(16b) [, des Sohnes, den du dir großgezogen hast].

(17a) Abgeschnitten ist er, im Feuer verbrannt,

(17b) vor deinem drohenden Antlitz kommen sie um.

(18a) Deine Hand sei über dem Mann deiner Rechten,

(18b) über dem Menschensohn, den du dir großgezogen hast.

(19a) Von dir werden wir nicht weichen;

(19b) schenke uns Leben, so wollen wir deinen Namen anrufen.

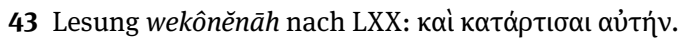


(20a) Jhwh [Gott] Zebaoth, stelle uns wieder her,

(20b) lass dein Angesicht leuchten, dann sind wir gerettet ${ }^{44}$ !

Sofort fällt in Ps 80 die strophische Gliederung ins Auge, wobei die Strophen mit einem Refrain schließen (V. 2-4.5-8.9-15b.15c-20). Der Refrain ist in Vers 4.8.20 weitgehend identisch, während er am Ende der dritten Strophe in Vers 15 variiert wird. Nimmt man diese auffällige Variante mit der Beobachtung zusammen, dass die dritte Strophe deutlich länger ist (V. 9-15: sieben Bikola) als die beiden ersten Strophen (V. 2-4. 5-8: je vier Bikola) und die letzte (V. 15-20: fünf Bikola), mag der Verdacht aufkommen, dass Ps 80 in der Grundfassung nur aus den drei gleichförmigen Strophen bestanden haben könnte und die dritte Strophe in Vers 9-15 nachträglich hinzugefügt worden sei. Doch dieser Gedanke ist abwegig, denn die vierte Strophe, die auch die Metapher des Weinstocks für das Gottesvolk gebraucht ${ }^{45}$, nimmt auf die vorangehende dritte Strophe Bezug. Die formale Ungleichheit der Strophen ist Ps 80 offensichtlich von Anfang an eigen. Die besonders auffällige dritte Strophe mit ihrem pointiert veränderten Refrain nutzt die Überlänge, um auch formal zu signalisieren, dass das im Psalm adressierte Verhältnis Gottes zu seinem Volk sich jeder Wohlordnung widersetzt. Dies wird auch durch den deutlich verschärften Ton der Anklage gegen Gott unterstrichen, in die auch der veränderte Refrain einbezogen wird. Zur Bitte, dass Gott das Volk wiederherstellen möge (šwb Hiphil, V. 4.8.20), gesellt sich in Vers 15 die anklagende Aufforderung, Gott möge umkehren (šwb Qal), nämlich sich abwenden von seinem Zorn, den nicht einmal das Gebet des Volkes zu besänftigen vermag (V. 5).

Die theologische Spitze von Ps 80 wird bereits durch Jhwhs Anrede als Hirte Israels vorbereitet. Sie ist für den Schutz, den Gottheiten und Könige gewähren, im Alten Orient weit verbreitet, wird aber im Alten Testament erst seit der Katastrophe von 587/6 v. Chr. stärker gebraucht, weil dadurch die Verantwortung Gottes für sein Volk mit Nachdruck eingeklagt werden kann ${ }^{46}$. Nicht vergleichbar konfrontativ wie in Jes 63,7-64,11, aber deutlich genug wird in Ps 80,2 der „Kerubenthroner“ (yōšēb hakkěrûbîm) aufgefordert, sich als Hirte von Joseph zu erweisen. Wegen der Nennung von Joseph muss man in Ps 80 keine alte Nord-

44 Ps 80 steht im Bereich von Ps 42-83, der eine inkonsequent durchgeführte elohistische Überarbeitung erfahren hat. Wo dadurch das Appellativum Elohim/Gott nunmehr im Text steht, ist es in der Übersetzung durch ,Jhwh' ersetzt oder als Zusatz eingeklammert worden. Zur Auslegung von Ps 80 vgl. Veijola 1982, 55-60.124-125; Hossfeld/Zenger 2000, $452-467$.

45 Zur Metapher des Weinstocks für Israel vgl. Ez 17,6-10; Hos 10,1; zur Metapher des Weinbergs vgl. Jes 5,1-7; 27,2-5.

46 Vgl. Spieckermann 1989, 266-268. 
reichtradition vermuten. Vielmehr ist der Joseph der Novelle von Gen 37-50 im Blick, ergänzt durch die, die besonders eng zu ihm gehören: der andere RahelSohn Benjamin und die beiden Söhne Josephs, Ephraim und Manasse. Der Kerubenthroner, der Hirte seines Volkes sein soll, möge an diese Geschichte aus Liebe und Leiden, aus Verrat und Versöhnung, aus Erniedrigung und Erhöhung denken. Was für Joseph galt, gilt nun für das Gottesvolk. Es hat alles verloren, was einst seine weltliche und theologische Existenz ausgemacht hat. Dieser Verlust ist dem Volk gleichsam zu Josephs Grube und Gefängnis geworden. Nur Jhwh kann Änderung bewirken. „Jhwh Zebaoth, stelle uns wieder her, lass dein Angesicht leuchten, dann sind wir gerettet!“ In Anspielung auf den aaronitischen Segen in Num 6,25, der schon in spätvorexilischer Zeit auf den Silberamuletten aus Ketef Hinnom bezeugt ist ${ }^{47}$, artikuliert der Refrain dreimal das theologische Ziel des Klage- und Bittgebets: die Wiederherstellung des Gottesvolkes ( $\check{w b}$ Hiphil). Sie setzt voraus, dass Jhwh seinen Segen als Rettung erfahrbar macht. Die dritte Strophe des Psalms (V. 9-15) spitzt theologisch noch schärfer zu. Jhwh selbst muss allererst umkehren (šwb Qal, V. 15a), damit eine Wiederherstellung des Gottesvolkes (šwb Hiphil) geschehen kann. In Übernahme von Jes 63,15a in Ps 80,15b heißt dies für Jhwh: Abkehr von seiner splendid isolation im Himmel $^{48}$.

Die Metapher des Weinstocks für das Gottesvolk - ein Bildwechsel gegenüber der Hirten- und Herdenmetaphorik - will auf dasselbe Ziel hinaus. Bewusst wird gesagt, dass Jhwhs Rechte den Weinstock gepflanzt habe. Daran knüpft die Selbstbezeichnung des Volkes als „Mann deiner Rechten“ in Vers 18a an, parallel zum Titel „Menschensohn“ in Vers 18b, den Gott großgezogen hat. Beide Selbstbezeichnungen sind anspruchsvoll. Hat der Titel „Menschensohn“

47 Vgl. Renz 1995, 447-456.

48 Von dieser splendid isolation ist Gott in Ps 75 weit entfernt, obwohl dieser Text zeitlich kaum weit entfernt von Ps 80 entstanden sein wird und nicht von ungefähr auch in die AsaphSammlung Ps 73-83 aufgenommen worden ist. Ps 75 scheint eine Reaktion auf den Vorwurf zu sein, dass Gott untätig ist. Hier bestimmt Gott selbst den Zeitpunkt seines gerechten Gerichts (V. 2), an dem er erniedrigen und erhöhen wird (V. 8). Diese Vorstellung impliziert hier nicht einen Sphärenwechsel Gottes, vielmehr widerfährt den Gerichteten nach Gottes Urteil Erniedrigung oder Erhöhung. Die Gewissheit des Beters, zu den Erhöhten zu zählen, ist so fest, dass er im abschließenden Gotteslob bereits seine Bereitschaft bekundet, die Hörner der Frevler zu zerbrechen (V. 11a; vgl. V. 5-6), denn „erhoben werden die Hörner des Gerechten“ (V. 11b). Ob im passivum divinum hier schon die Vorstellung präsent ist, dass Gott dem Gerechten eine Erhöhung zuteilwerden lässt, die einem Sphärenwechsel gleichkommt? Ps 76 verstärkt die Erwartung des rettenden Gerichts Gottes. Hier sind Salem und Zion Ort(e) seiner Gegenwart (V. 3.), nicht zu trennen vom Himmel, von dem aus Gott sein Gericht vernehmbar macht, um alle Elenden der Erde zu retten (V. 9-10). 
als Gottes Anrede an den Propheten Ezechiel in der nachexilischen Profilierung des ihm zugeschriebenen Buches Reputation gewonnen, ist die Anspielung beim Titel „Mann deiner Rechten“ auf die Einladung Gottes an den König zur sessio ad dexteram in Ps 110,1 unüberhörbar. Dies wird auch dadurch untermauert, dass die Ergänzung in Ps 80,16b an die Stelle des Menschensohnes den Sohn setzt, eine kollektive Aneignung dieses Königstitels (vgl. Ps 2,7) durch das leidende Volk. Besonders aber unter dem Titel „Mann deiner Rechten“ bietet sich das den Hirten entbehrende, zerstreute Judentum Jhwh als Erben der Verheißung an David an. Gleiches unternimmt das Volk in beschwörender Anklage unter dem Titel „Messias“ in Ps 89,50-52 ${ }^{49}$ und unter demselben Titel in vertrauensvoller Antizipation der Rettung in Ps 20,7. Nicht von ungefähr handelt Jhwh hier von seinem heiligen Himmel her „mit rettenden Machttaten seiner Rechten ${ }^{* 50}$.

Wie Jes 63,7-64,11, wenn auch weniger provokativ, erfleht Ps 80 den Sphärenwechsel Jhwhs. Er wird nicht in diesem Psalm, sondern in Ps 113 gewährt, einem Hymnus, der die Psalmenkomposition Ps 113-118 einleitet, welche schon im Judentum vor der Zeitenwende als das Pesach-Hallel große Bedeutung gehabt hat (vgl. 2Chr 30,21; 35,15; Jub 49,6; Sap 18,9; Mk 14,26).
(1a) Hallelujah!
(1b) Lobt, ihr Knechte Jhwhs,
(1c) lobt Jhwhs Namen.
(2a) Der Name Jhwhs sei gepriesen
(2b) von nun an bis in Ewigkeit.
(3a) Vom Aufgang der Sonne bis zu ihrem Niedergang
(3b) sei Jhwhs Name gelobt.
(4a) Jhwh ist erhaben ( $r w m$ Qal) über alle Völker
(4b) über den Himmel seine Herrlichkeit.
(5a) Wer ist wie Jhwh, unser Gott,
(5b) der erhöht ( $g b h$ Hiphil), um zu thronen (yšb Qal),
(6a) der in die Tiefe geht (špl Hiphil), um zu schauen
(6b) im Himmel und auf Erden,

49 Es handelt sich um eine nachexilische, kollektive Aneignung des vorexilischen Jhwh/VaterKönig/Sohn-Verhältnisses aus 2Sam 7,14a.16 in Ps 89,21-38; vgl. Feldmeier/Spieckermann 22017, 56-66.

In diesen Zusammenhang gehört auch der noch jüngere Ps 132, der dezidiert Zion zu dem Ort macht, an dem in fortgeschrittener nachexilischer Zeit königliche und priesterliche Traditionen ebenso wieder ihre Heimat finden wie das Gottesvolk, das sich nicht ohne Stolz als „Arme“ ('ebyônîm) und „Treue“ (hăsîdîm) charakterisiert (V. 15-16); vgl. Feldmeier/Spieckermann 2018, 99-105.

50 Zu Ps 20 vgl. Salo 2017, 54-96; Feldmeier/Spieckermann 2018, 43-45. 
(7a) der aus dem Staub den Geringen (dal) aufrichtet ( $q w m$ Hiphil),

(7b) aus dem Schmutz den Armen ('ebyôn) erhebt (rwm Hiphil),

(8a) um (sie) thronen zu lassen ( $y$ šb Hiphil) bei Edlen (nědîbîm),

(8b) bei den Edlen seines Volkes,

(9a) der die Unfruchtbare ('aqeret) des Hauses thronen lässt ( $y s ̌ b$ Hiphil),

(9b) eine frohe Mutter von Söhnen/Kindern.

(9c) Hallelujah!

Auf die Lobaufforderung in Vers 1 folgt in Vers 2-4 die Entfaltung von Jhwhs universaler Erhabenheit und Herrlichkeit, die selbst über den Himmel hinaus reicht, welcher in den bisher behandelten Texten als eine Art cordon sanitaire für ihn fungiert hat. Die in Vers 5a folgende Unvergleichlichkeitsprädikation Jhwhs, dem jetzt zudem das Attribut „unser Gott“ zuteil wird, ist vom Aufbau des Textes her das Zentrum. Das zugehörige Kolon (V. 5b) gehört durch die Eröffnung der folgenden Reihe hymnischer Partizipien schon ganz zum zweiten Teil (V. 6-9). Es stellt sich der Eindruck ein, dass der Text gar nicht schnell genug zur Explikation fortschreiten kann, worin Jhwhs Unvergleichlichkeit besteht ${ }^{51}$.

Vers $5 b$ teilt etwas auf den ersten Blick Unverständliches mit. Die Übersetzungen wählen in der Regel den Weg, dass sie Jhwh noch einmal hoch oben thronen lassen. Dies tut er jedoch nach Auskunft von Vers 2-4 ohnehin, so dass in Vers 5 etwas anderes im Blick sein wird. Bewusst wird die Unvergleichlichkeitsaussage von Vers 5a mit der Apposition „unser Gott“ verbunden, so dass bereits für Vers $5 \mathrm{~b}$ gelten wird, was auch auf die folgende Reihe der hymnischen Partizipien (unter Einschluss eines Infinitivs) zutrifft. Sie alle lassen wissen, was diesen Gott als „unseren Gott“ lobenswert macht. Es ist die Erhöhung der Armen, Schwachen und Unfruchtbaren (V. 7-9). Sie sind diejenigen, von denen Jhwh als seinen Knechten (V.1) das Lob empfangen möchte. Dass gerade sie beim Lob willkommen sind, macht Gott durch seine besondere Zuwendung deutlich, von der Vers 5b spricht. Danach erhöht Jhwh nicht genannte Personen lāšābat „um Platz zu nehmen“; im königlichen Milieu ist damit das Platznehmen auf dem Thron gemeint. Zwar ist Ps 113 prima facie überhaupt nicht im königlichen Milieu zu verorten, doch Jhwhs Einladung zur Einnahme des Thrones an den König steht nicht weit entfernt. Sie ist in Ps 110,1 zu finden, wo Jhwh den König zum Thronen, nämlich zur sessio ad dexteram auffordert. Darauf wird in Ps 113 Bezug genommen.

51 Zur Auslegung von Ps 113 vgl. Hossfeld/Zenger 2008, 248-255; zu den Unvergleichlichkeitsprädikationen vgl. Labuschagne 1966. 
Es ist evident, welches Ziel die auffällige Formulierung des Thronens in Ps 113,5 unter Bezugnahme auf Ps 110,1 verfolgt. Der unvergleichlich erhabene Jhwh ist darin „unser Gott“, dass er zum Thronen in seiner Nähe die bestimmt, zu deren Erhöhung er sich in die Tiefe begeben muss: die Schwachen, die Armen, die Unfruchtbaren ${ }^{52}$. Sie sind die wahren Knechte Jhwhs - die Septuaginta übersetzt mit Bedacht und Wertschätzung $\pi \alpha \tilde{I} \delta \varepsilon \varsigma^{53}$. Sie sind die Edlen, denen die königgleiche Erhöhung zuteil wird, wie die zweifache Aufnahme der Wurzel yšb Hiphil „wohnen/thronen lassen“ (V. 8-9) für die Genannten deutlich macht.

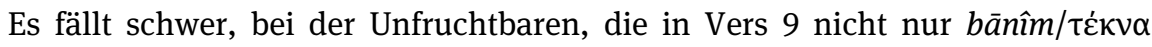
„Söhne/Kinder“ bekommt, sondern auch ein bayit „Haus“ hat - im königlichen Milieu das Lexem für Dynastie (2Sam 7,11-12) -, nicht an die in Jes 54 nicht mit Namen genannte Frau Zion zu denken ${ }^{54}$. Ps 113 als Introitus des Pesach-Hallels setzt klare Akzente, dass Gott das Überraschende an denen tut, die als bedürftige und notvolle Geschöpfe seine Nähe suchen und durch sein rettendes Handeln Erhöhung erfahren, die nur in königlicher Terminologie angemessen gesagt werden kann. Dasselbe gilt für den Abschluss des Pesach-Hallels durch Ps 118, wo in Vers 14-18 Jhwhs Rechte - kaum ohne Kenntnis von Ps 110 - die Gerechten in einer Weise rettet und erhöht, dass sie Gottes Tat als Wende vom Tod zum Leben erfahren ${ }^{55}$. So vollzieht Jhwh den Sphärenwechsel. Der Weg ist gefunden, wie Königstheologie in königloser Zeit soteriologisch aktualisiert werden kann. Ohne Ps 113 und 118 wären der Lobgesang der Hannah in 1 Sam 2,1-10 und das Magnificat der Maria in Lk 1,46-55 undenkbar ${ }^{56}$.

52 Es besteht eine Nähe zu Ps 102,13-23, obwohl beide Psalmen eine je eigene Sprache und Vorstellungswelt haben.

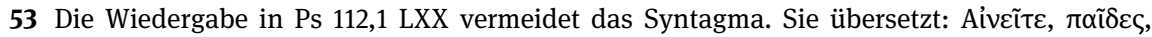
kúpıov „Lobt, ihr Knechte, den Herrn!“ Vielleicht will der Übersetzer einerseits zum Titel raĩs kupíov für den Gottesknecht in Jes 41,6; 42,2 et al. Distanz halten, andererseits aber auf die mit

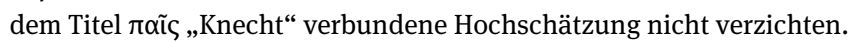

54 Vgl. Feldmeier/Spieckermann 2018, 161-164.

55 Zu Ps 118 vgl. Schröten 1995; Schmidt 2014, 105-123; Feldmeier/Spieckermann 22017, 540546; zu Ps 113 und 118 als Rahmen des Pesach-Hallels vgl. Feldmeier/Spieckermann 2018, 166172.

56 Vgl. Lohfink 1990; zum traditionsgeschichtlichen Vorlauf des Erniedrigens in der Schriftprophetie als Voraussetzung zur später hinzutretenden Vorstellung der Erhöhung vgl. Schöpflin 2012, 5-22. 


\section{Fazit}

Die vorexilische Jerusalemer Königstheologie bringt die enge Bindung zwischen Jhwh und dem jeweiligen Herrscher auf dem Davidsthron durch das VaterSohn-Verhältnis zum Ausdruck, welches Jhwh dem König bei der Inthronisation gewährt, woran im Kult wahrscheinlich jährlich erinnert wird. Zion - Ort sowohl des Tempels als auch des Palastes - hat dabei eine besondere Stellung, denn diese im Hebräischen feminine Stätte vereint göttliche und königliche Präsenz so intensiv, dass das Handeln Gottes und dasjenige des Königs vom Zion aus gegen die aufbegehrende Feindwelt bewusst nicht klar unterschieden werden. Zion ist gleichermaßen der Ort des Himmelsthroners Jhwh wie des inthronisierten Königs. Hier findet die sessio ad dexteram statt und dadurch zugleich die Abwehr der Feinde. Zion absorbiert Zaphon, den prominentesten, sogar divinisierten Gottesberg der altsyrischen Tradition. Zion ist Gottesberg und zugleich Thronsitz der Davididen. In Übereinstimmung damit bezeichnet bayit „Haus“ zugleich den Tempel, den Palast und die Dynastie. In der vorexilischen Tempel-Palast-Theologie durchdringen göttliche und königliche Sphäre einander, so dass sich Vorstellungen eines Sphärenwechsels - sei es Gottes, sei es des Königs - nicht nahe legen.

Diese Theologie verliert 587/6 v. Chr. durch den Verlust des Tempels und der Daviddynastie ihr Fundament. In den folgenden tempel- und königlosen Jahrzehnten werden in theologischen Kontroversen neue Einsichten erlitten und erstritten. Die große Verliererin ist zunächst Zion, wo Tempel und Palast beieinander gewesen sind. Im deuterojesajanischen Schrifttum und in den Threni wird Zion zur Frau, die Gott verstoßen hat und die ihrer Kinder beraubt ist. Zur Klage um den erlittenen Verlust gesellt sich die bedrängende Frage, wo Gott nunmehr präsent sei. Der Himmel, der als Ort seiner Gegenwart in Einheit mit Zion verloren hat, gerät in Verdacht, Gottes Refugium zu sein, wo er sich die Katastrophe seines Volkes auf Distanz hält. Doch das Volk beharrt auf dem Erbanspruch der göttlichen Verheißung an David, dass seine Dynastie ewig währen soll. Wird auch das Königtum zunehmend Gott überlassen, pochen die leidenden Erben auf ihren Anteil: das Erbe Davids als bisher ausgebliebene Erfahrung rettender Gottesnähe.

Gott gewährt diese Nähe in nachexilischer Zeit, indem er sich aus den Höhen tief niederbeugt und die um Rettung Flehenden königlich erhöht. Erst in nachexilischer Zeit gewinnt die Vorstellung von Sphärenwechseln Relevanz als Gottes Tat in soteriologischer Absicht. Mit hoher Wahrscheinlichkeit ist sie erst möglich geworden, nachdem 515 v. Chr. der Zweite Tempel eingeweiht worden ist. Angesichts des Zweiten Tempels hat nachexilische Prophetie Zion und zu- 
nehmend Jerusalem - beide als „heilige Stadt“ - zum Topos rettender, eschatologischer Gottespräsenz gemacht. Auf ganz andere Weise macht das priesterliche Schrifttum die Kondeszendenz der Herrlichkeit Gottes im Allerheiligsten des Tempels, welche nie mit Zion in Verbindung gebracht wird, zur entscheidenden Voraussetzung für Gottes Sühnehandeln im Opferkult ${ }^{57}$. Dies ist theologisch eine ganz andere Welt als Gottes Sphärenwechsel in den Psalmen, durch den er seinen Rettungswillen für die Rettung Erflehenden verwirklicht. Im Gefolge dieser zunächst theozentrisch konzipierten Vorstellung werden in der Folgezeit wieder Mittler in der Apokalyptik Bedeutung gewinnen, die durch Katabasis und Anabasis über Gottes-, Himmel- und Höllenkunde verfügen. Schließlich wird von Einem gesagt werden, dass in ihm der rettende Gott Mensch geworden sei.

\section{Bibliographie}

Assmann, J., 1984, Ägypten - Theologie und Frömmigkeit einer frühen Hochkultur, UniTaschenbücher 366, Stuttgart.

Becker, J., 1986, Zur Deutung von Ps 110,7, in: Haag, E. / Hossfeld, F.-L. (Hg.), Freude an der Weisung des Herrn (FS H. Groß), Stuttgarter biblische Beiträge 13, Stuttgart, 17-31.

Berner, C., 2010, Die Exoduserzählung. Das literarische Werden einer Ursprungslegende Israels, Forschungen zum Alten Testament 73, Tübingen.

Bertholet, A., 1908, Eine crux interpretum. Ps 2,11 f, Zeitschrift für die alttestamentliche Wissenschaft 28, 58-59.

Braulik, G., 2018, „Du bist doch unser Vater! ,Unser Erlöser von jeher‘ ist dein Name“. Wie Israel als Volk um die Vergebung seiner Schuld bittet, Internationale Katholische Zeitschrift 47, 1-18.

Brunner, H., 1986, Die Geburt des Gottkönigs. Studien zur Überlieferung eines altägyptischen Mythos, Ägyptologische Abhandlungen 10, Wiesbaden (zweite ergänzte Auflage).

Cole, R. L., 2013, Psalms 1-2. Gateway to the Psalter, Hebrew Bible Monographs 37, Sheffield.

del Olmo Lete, G. / Sanmartín, J., 2004, A Dictionary of the Ugaritic Language in the Alphabetic Tradition, Handbook of Oriental Studies I 67, Leiden/Boston, MA (zweite überarbeitet Auflage).

Dietrich, M. / Loretz, O. / Sanmartín, J., 1995, The Cuneiform Alphabetic Texts from Ugarit, Ras Ibn Hani and Other Places (CAT; KTU: second, enlarged edition), Abhandlungen zur Literatur Alt-Syrien-Palästinas und Mesopotamiens 8, Münster.

Donner, H., siehe Gesenius, W.

Feldmeier, R. / Spieckermann, H., 2018, Menschwerdung, Topoi Biblischer Theologie 2, Tübingen. Feldmeier, R. / Spieckermann, H., 2017, Der Gott der Lebendigen. Eine biblische Gotteslehre, Topoi Biblischer Theologie 1, Tübingen (zweite Auflage).

57 Vgl. Janowski ${ }^{2} 2000$, 295-346. 
García Martínez, F. / Tigchelaar, E. J. C., 1997, The Dead Sea Scrolls. Study Edition, 2 Bände, Leiden.

Gesenius, W. / Donner, H., 2013, Hebräisches und Aramäisches Handwörterbuch über das Alte Testament, Heidelberg (18. Auflage).

Gillingham, S., 2013, A Journey of Two Psalms: The Reception of Psalms 1 and 2 in Jewish and Christian Tradition, Oxford.

Granerød, G., 2010, Abraham and Melchizedek. Scribal Activity of Second Temple Times in Genesis 14 and Psalm 110, Beihefte zur Zeitschrift für die alttestamentliche Wissenschaft 406, Berlin / New York, NY.

Grohmann, M., 2007, Fruchtbarkeit und Geburt in den Psalmen, Forschungen zum Alten Testament 53, Tübingen.

Hamilton, M. W., 2005, The Royal Body. The Social Poetics of Kingship in Ancient Israel, Atlanta, GA.

Hartenstein, F. / Janowski, B., 2012, Psalmen, Biblischer Kommentar XV/1, Neukirchen-Vluyn. Helck, W., 1979, Die Beziehungen Ägyptens und Vorderasiens zur Ägäis bis ins 7. Jahrhundert v. Chr., Erträge der Forschung 120, Darmstadt.

Hossfeld, F.-L. / Zenger, E., 1993, Psalm 1-50, Neue Echter Bibel, Würzburg.

Hossfeld, F.-L. / Zenger, E., 2000, Psalmen 51-100, Herders Theologischer Kommentar zum Alten Testament, Freiburg.

Hossfeld, F.-L. / Zenger, E., 2008, Psalmen 101-150, Herders Theologischer Kommentar zum Alten Testament, Freiburg.

Janowski, B., 2001, Der Himmel auf Erden. Zur kosmologischen Bedeutung des Tempels in der Umwelt Israels, in: Janowski, B. / Ego, B., Das biblische Weltbild und seine altorientalischen Kontexte, Forschungen zum Alten Testament I/32, Tübingen, 229-260.

Janowski, B., 2000, Sühne als Heilsgeschehen. Traditions- und religiornsgeschichtliche Studien zur Sühnetheologie der Priesterschrift, Wissenschaftliche Monographien zum Alten und Neuen Testament 55, Neukirchen-Vluyn (1982)(zweite ergänzte und erweiterte Auflage).

Janowski, B., siehe Hartenstein, F.

Keel, O., 1980, Die Welt der altorientalischen Bildsymbolik und das Alte Testament. Am Beispiel der Psalmen. Zürich/Neukirchen-Vluyn (dritte Auflage).

Koch, K., 1993, Geschichte der ägyptischen Religion. Von den Pyramiden bis zu den Mysterien der Isis, Stuttgart.

Koch, K., 2002, Der König als Sohn Gottes in Ägypten und Israel, in: Otto, E. / Zenger, E. (Hg.), „Mein Sohn bist du“ (Ps 2,7). Studien zu den Königspsalmen, Stuttgarter Bibel-Studien 192, Stuttgart, 1-32.

Körting, C., 2006, Zion in den Psalmen, Forschungen zum Alten Testament 48, Tübingen.

Krusche, M., 2019, Göttliches und irdisches Königtum in den Psalmen, theol. Diss. Göttingen 2018 (erscheint Tübingen 2019).

Labuschagne, C. J., 1966, The Incomparability of Yahweh in the Old Testament, Pretoria Oriental Series 5, Leiden.

Lohfink, N., 1990, Lobgesänge der Armen. Studien zum Magnifikat, den Hodajot von Qumran und einigen späten Psalmen, Stuttgarter Bibel-Studien 143, Stuttgart.

Loretz, O., siehe Dietrich, M.

Mettinger, T. N. D., 1976, King and Messiah. The Civil and Sacral Legitimation of the Israelite Kings, Coniectanea Biblica, Old Testament Series 8, Lund. 
Niehr, H., 2003, Ba'alšamem. Studien zur Herkunft, Geschichte und Rezeptionsgeschichte eines phönizischen Gottes, Orientalia Lovaniensia analecta 123, Leuven.

Niehr, H., 2015, Texte aus Syrien: in: Janowski, B. / Schwemer, D. (Hg.), Texte aus der Umwelt des Alten Tesaments. Neue Folge Bd. 8: Weisheitstexte, Mythen und Epen, Gütersloh, 177-301.

Nordheim, M. von, 2008, Geboren von der Morgenröte? Psalm 110 in Tradition, Redaktion und Rezeption, Wissenschaftliche Monographien zum Alten und Neuen Testsament 117, Neukirchen-Vluyn.

Pitard, W. T., siehe Smith, M. S.

Renz, J., 1995, Die althebräischen Inschriften Bd. I/1, Darmstadt.

Salo, R. S., 2017, Die judäische Königsideologie im Kontext der Nachbarkulturen, Orientalische Religionen in der Antike 25, Tübingen.

Sanmartín, J., siehe del Olmo Lete, G. und Dietrich, $M$.

Saur, M., 2004, Die Königspsalmen. Studien zur Entstehung und Theologie, Beihefte zur Zeitschrift für die alttestamentliche Wissenschaft 340, Berlin / New York, NY.

Schmidt, W. H., 2014, „Der tötet und lebendig macht.“ Elemente biblischer Theologie aus alttestamentlicher Sicht (2009), in: ders., Gottes Wirken und Handeln des Menschen. Zum Verständnis des Alten Testaments und seiner Bedeutung für den christlichen Glauben, Biblisch-Theologische Studien 147, Neukirchen-Vluyn, 105-123.

Schmidt, W. H., 1966, Königtum Gottes in Israel und Ugarit. Zur Herkunft der Königsprädikation Jahwes, Beihefte zur Zeitschrift für die alttestamentliche Wissenschaft 80, Berlin (zweite neubearbeitete Auflage).

Schöpflin, K., 2012, „... denn er hat die Niedrigkeit seiner Magd angesehen“ (Lk 1,48). Gedan-

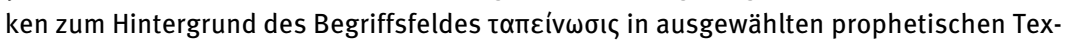
ten der Septuaginta, Biblische Notizen 155, 5-22.

Schröten, J., 1995, Entstehung, Komposition und Wirkungsgeschichte des 118. Psalms, Bonner Biblische Beiträge 95, Weinheim.

Smith, M. S., 2006, The Rituals and Myths of the Feast of the Goodly Gods of KTU/CAT 1.23. Royal Constructions of Opposition, Intersection, Integration, and Domination, Atlanta, GA.

Smith, M. S. / Pitard, W. T., 2009, The Ugaritic Baal Cycle Bd. II, Supplements to Vetus Testamentum 114, Leiden / Boston MA.

Spans, A., 2015, Die Stadtfrau Zion im Zentrum der Welt. Exegese und Theologie von Jes 60-62, Bonner Biblische Beiträge 175, Göttingen.

Spieckermann, H., 1989, Heilsgegenwart. Eine Theologie der Psalmen, Forschungen zur Religion und Literatur des Alten und Neuen Testaments 148, Göttingen.

Spieckermann, H., 1992, Stadtgott und Gottesstadt. Beobachtungen im Alten Orient und im Alten Testament, Biblica 73, 1-31.

Spieckermann, H., 2013, Historiography, „Rod of My Anger“, and Covenant. The Impact of Asshur on the Old Testament, in: Obara, M. E. / Succu, G. P. D. (Hg.), Uomini e profeti. Festschrift für H. Simian Yofre SJ, Analecta Biblica 202, Roma, 319-342.

Spieckermann, H., siehe Feldmeier, R.

Stadelmann, R., 1967, Syrisch-palästinische Gottheiten in Ägypten, Probleme der Ägyptologie 5 , Leiden.

Steudel, A., 1994, Der Midrasch zur Eschatologie aus der Qumrangemeinde (4QMidrEschata.b), Studies on the Texts of the Desert of Judah 13, Leiden.

Steudel, A., 2001, Die Texte aus Qumran. Hebräisch/Aramäisch und Deutsch, Bd. 2, Darmstadt. Tigchelaar, E. J. C., siehe García Martínez, F. 
Veijola, T., 1982, Verheißung in der Krise. Studien zur Literatur und Theologie der Exilszeit anhand des 89. Psalms, Annales Academiae Scientiarum Fennicae B 220, Helsinki.

Watson, W. G. E., 1993, The Goddesses of Ugarit: A Survey, Studi epigrafici e linguistici sul Vicino Oriente antico 10, 47-59.

Wilke, A. F., 2014, Die Gebete der Propheten. Anrufungen Gottes im ,corpus propheticum‘ der Hebräischen Bibel, Beihefte zur Zeitschrift für die alttestamentliche Wissenschaft 451, Berlin / Boston, MA.

Zenger, E., 1986, „Wozu tosen die Völker...?“ Beobachtungen zur Entstehung und Theologie des 2. Psalms, in: Haag, E. / Hossfeld, F.-L. (Hg.), Freude an der Weisung des Herrn (FS H. Groß), Stuttgarter biblische Beiträge 13, Stuttgart, 495-511.

Zenger, E., siehe Hossfeld, F.-L. 
